\title{
Jet-Pylon Interaction of High Bypass Ratio Separate Flow Nozzle Configurations
}

\author{
Russell H. Thomas* and Kevin W. Kinzie ${ }^{*}$ \\ NASA Langley Research Center, Hampton, Virginia, 23681-0001 USA
}

\begin{abstract}
An experimental investigation was performed of the acoustic effects of jet-pylon interaction for separate flow and chevron nozzles of both bypass ratio five and eight. The models corresponded to an approximate scale factor of nine. Cycle conditions from approach to takeoff were tested at wind tunnel free jet Mach numbers of 0.1, 0.2 and 0.28. An eight-chevron core nozzle, a sixteen chevron fan nozzle, and a pylon were primary configuration variables. In addition, two orientations of the chevrons relative to each other and to the pylon were tested. The effect of the pylon on the azimuthal directivity was investigated for the baseline nozzles and the chevron nozzles. For the bypass ratio five configuration, the addition of the pylon reduces the noise by approximately 1 EPNdB compared to the baseline case and there is little effect of azimuthal angle. The core chevron produced a 1.8 EPNdB reduction compared to the baseline nozzle. Adding a pylon to the chevron core nozzle produces an effect that depends on the orientation of the chevron relative to the pylon. The azimuthal directivity variation remains low at less than 0.5 EPNdB. For the bypass ratio eight configuration the effect of adding a pylon to the baseline nozzle is to slightly increase the noise at higher cycle points and for the case with a core chevron the pylon has little additional effect. The azimuthal angle effect continues to be very small for the bypass ratio eight configurations. A general impact of the pylon was observed for both fan and core chevrons at both bypass ratios. The pylon reduces the typical low frequency benefit of the chevrons, even eliminating it in some cases, while not impacting the high frequency. On an equal ideal thrust basis, the bypass ratio eight baseline nozzle was about 5 EPNdB lower than the bypass ratio five baseline nozzle at the highest cycle condition, however, with a pylon installed the difference decreased to about 4 EPNdB.
\end{abstract}

\section{Nomenclature}

$\begin{array}{ll}\text { AST } & =\text { Advanced Subsonic Transport } \\ \mathrm{BPR} & =\text { bypass ratio } \\ \mathrm{D} & =\text { nozzle diameter } \\ \mathrm{EPNL} & =\text { effective perceived noise level } \\ \mathrm{JES} & =\text { Jet Engine Simulator } \\ \text { LSAWT } & =\text { Low Speed Aeroacoustics Wind Tunnel } \\ \mathrm{Mfj} & =\text { Free jet Mach number } \\ \mathrm{NPR} & =\text { nozzle pressure ratio } \\ \mathrm{PNL} & =\text { perceived noise level } \\ \mathrm{SPL} & =\text { sound pressure level } \\ \mathrm{TT} & =\text { total temperature } \\ \mathrm{R} & =\text { Degrees Rankine } \\ \mathrm{Vmix} & =\text { mixed jet velocity, ft/s } \\ \theta & =\text { polar directivity angle theta, degrees, jet axis at } 180 \text { degrees }\end{array}$

\footnotetext{
${ }^{*}$ Senior Research Engineer, Aeroacoustics Branch, MS 166, and AIAA Senior Member. 


\section{Introduction}

Over the past several decades there has been a continued focused effort to reduce the engine component source noise in order to reduce the highest levels of noise of commercial subsonic transport aircraft. More recently, as engine sources were reduced in large part by high bypass ratio engines, the sources of airframe noise have been investigated as well because of their importance at the approach conditions. In addition to these engine and airframe sources other means of reducing the total aircraft system noise impact on the community have been brought to the forefront of research as additional increments of noise reduction are increasingly difficult to produce. One such opportunity for additional increments of noise reduction centers on the aeroacoustic effects of propulsion airframe integration, that is, propulsion airframe aeroacoustics.

As such, propulsion airframe aeroacoustics has been relatively underdeveloped and represents an area of opportunity to develop noise reduction technology for conventional configurations. This opportunity includes both reducing the noise sources that arise specifically from integration of propulsion and airframe and also using the installation itself as a means to reduce noise of a particular airframe or propulsion source ${ }^{1}$.

In general, there are many propulsion airframe aeroacoustic effects that can be identified and they can be grouped in various ways. Fundamental effects can be grouped into those issues having to do with flow interaction and those having to do with acoustic propagation although these are not entirely unrelated issues. Flow interaction effects are caused by the flow field of one component interacting with another specifically because of the location or orientation of installation. An example of this is the influence of the engine mounting pylon on the jet exhaust flow. These types of flow interaction effects from installation can create new acoustic sources or they can modify existing acoustic sources.

Jet noise from a conventional engine-under-the-wing configuration can have installation effects of both the flow interaction and the acoustic propagation types from the pylon, wing, and flap interaction and there can also be installation effects on jet noise reduction devices installed on the jet. Chevron nozzles are an example of a jet noise reduction device that has been studied extensively in recent years ${ }^{2,3}$. The influence of the pylon alone on the jet creates flow features in the jet that are not present in an isolated jet. One area of research, therefore, has been toward understanding these effects of the jet-pylon interaction including the effects on chevron noise reduction devices.

Recent work in the area of jet-pylon interaction has included a study of the azimuthal effects of a pylon. Bhat ${ }^{4}$ tested a $1 / 20^{\text {th }}$ scale model of a bypass ratio five separate flow nozzle to measure the effect of the pylon relative to the baseline axisymmetric nozzle. The effect of adding the pylon was found to add $0.5 \mathrm{EPNdB}$ to $1.0 \mathrm{EPNdB}$ relative to the baseline. With the pylon installed, a variation in azimuthal directivity was measured of about 2 EPNdB at low power settings and 3.5 EPNdB at high power settings. No chevron nozzles were included in this study. Martens ${ }^{3}$ included a chevron core nozzle and a pylon in the acoustic results from the test of a bypass ratio five separate flow nozzle. The chevron core nozzle produced a 2-3 EPNdB reduction compared to the baseline core nozzle for this $1 / 11^{\text {th }}$ scale model of the CFM56-5B exhaust system. For both baseline and chevron nozzles, differences of 1-2 EPNdB were noticed for the two azimuthal angles tested corresponding to the sideline and the cutback certification locations.

The work in this paper will focus on the experimental investigation of jet-pylon effects for separate flow and chevron nozzles of both bypass ratio five and eight. These experiments measured the mean flow quantities of pressure and temperature (previously reported in Massey et. al. ${ }^{5}$ ) and the acoustic effects reported here. The models corresponded to an approximate full scale to model scale factor of nine. Cycle conditions representing those from a typical subsonic aircraft at approach to takeoff were tested at wind tunnel free jet Mach numbers of $0.1,0.2$ and 0.28 . An eight-chevron nozzle and a pylon were primary configuration variables. In addition, two orientations of the chevrons relative to the pylon were tested. The effect of the pylon and the azimuthal directivity were investigated for the baseline nozzles and the chevron nozzles.

\section{Experimental Approach}

The experiments reported here were carried out at NASA Langley's Jet Noise Laboratory and were concluded by the summer of 2002. The purpose was to provide an experimental database of acoustic and mean flow surveys of a basic building block of propulsion airframe integration, the jet-pylon interaction. The components of the experiment consisted of the Jet Engine Simulator, the Low Speed Aeroacoustic Wind Tunnel, and the model hardware.

\section{A. Experimental Facility}

The Jet Engine Simulator (JES) is installed in the Low Speed Aeroacoustic Wind Tunnel (LSAWT) to produce two streams to accurately simulate engine nozzle systems. The JES has two propane fired sudden expansion burners 
to heat fan and core nozzle streams separately. Each stream can flow air up to a maximum of $17 \mathrm{lbm} / \mathrm{sec}$. In addition, each stream has an electric pre-heater for low temperature operation and for burner stability. Airflow is straightened before transitioning to the nozzle. The JES is equipped with a six component load cell for thrust measurements although that capability was not used in this experiment. Airflow is measured by critical venturies in each stream. Fuel flow is measured by turbine meters. Airflow pressure and temperature rakes are positioned just upstream of the nozzle contraction to measure nozzle conditions.

The LSAWT is a continuous flow in-draft wind tunnel that provides a free jet surrounding the JES exhaust flow. The free jet is produced by a 4.7 foot square nozzle. The JES is positioned in the free jet nozzle and test section as shown in Figure 1. Wind tunnel speed can be varied from a Mach number of 0.1 up to 0.32 . For this experiment the wind tunnel free jet was run at three Mach numbers, $0.1,0.2$, and 0.28 .

The test section has anechoic treatment from fiberglass wedges and the cut-off frequency is $250 \mathrm{~Hz}$. Dimensions of the test cell, measured from tip-to-tip of the wedges is 34 feet long by 17 feet high by 17 feet wide. The downstream flow collector regulates flow recirculation in the test cell. Both the wind tunnel nozzle and the flow collector are acoustically treated to minimize reverberations.

\section{B. Model Design and Experimental Configurations}

The baseline configurations are BPR five and eight separate flow nozzles with an external plug. The nozzle and pylon design are from a nozzle study performed by McDonnell Douglas (now Boeing) in 1996 and represents a generic design of conventional nozzles for commercial subsonic transports. The baseline nozzles, with pylon or chevrons, have the same fan nozzle for both BPR five and eight. The higher bypass ratio is achieved by reducing the diameter of the core nozzle from 5.04 inches to 4.70 inches.

Chevrons are a noise reduction technology that is rapidly being applied to newer engine nozzles and since the pylon is an integral part of the nozzle, core and fan chevrons were tested with and without a pylon at both bypass ratios. On the baseline nozzles, when fan and core chevrons were installed, the orientation of the core and fan chevrons relative to each other was tested. When a pylon was installed, two orientations of the core chevrons relative to the pylon were tested. These two orientations occur when a chevron trough is aligned with the pylon centerline and again when a chevron tip is aligned with the pylon centerline. The chevrons were designed for the core nozzle using guidelines similar to those used in the NASA Advanced Subsonic Transport program ${ }^{6}$. The chevrons were designed to penetrate into the core flow by approximately the estimated thickness of the boundary layer for the BPR five nozzle. For the BPR eight nozzle the core chevrons did not penetrate. The trailing edge of the baseline nozzle is chosen to correspond to the mid-point of the chevron axial length.

Since the pylon clearly introduces a non-axisymmetric geometry, azimuthal angle was also variable in the experimental matrix. Three azimuthal angles were used as shown in Figure 3 including an orientation corresponding to a flyover (90 degrees), a sideline or takeoff angle (34 degrees) and a third angle at 0 degrees that is normal to the line from the microphones to the nozzle centerline. To achieve the different azimuthal angles the microphones remain fixed and the model with pylon is rotated.

The pylon in these configurations has a diverging angle of 1.5 degrees for the shelf of the pylon that the core flow follows. The junction of the core nozzle with chevrons and the pylon shelf is simply the result of a separate chevron and pylon design combined with no added design feature for the junction. A typical nozzle configuration used in this experiment is shown in Figure 2. This picture shows the BPR five nozzle with a baseline fan nozzle, an eight chevron core nozzle with a chevron tip aligned with the pylon. The pylon was added to the same baseline fan nozzle. Therefore, the fan nozzle area for a configuration with a pylon is less than the fan nozzle area for a baseline configuration. As will be described in sections below, the reduced area, for the same nozzle flow condition, means less fan area and less thrust. Table 1 summarizes the total nozzle areas for both BPR five and eight baseline and pylon configurations. The model scale area at cold (room temperature) conditions are based on measurements of the nozzles and are of the area normal to the inner surface at the exit of the nozzle as opposed to an area in the vertical plane at the exit. During the experiment, the nozzle operates at elevated temperatures (section II. C) and thermal expansion causes the nozzle system dimensions to change slightly. The dimensions under hot operating conditions are not measured, but are estimated based on the known thermal expansion coefficients. These estimated areas under hot operating conditions are also shown in Table 1. The pylon has an axial split line that allows for thermal growth between the core and fan nozzles and can be seen in Figure 2. The gap between the two parts of the pylon is typically less than 0.04 inches and is sealed to prevent air leakage. Chevron nozzles were assumed to have the same exit area as the corresponding baseline nozzle. Also in Table 1 are the scale factors (based on hot areas) used for processing of the acoustic data as will be described later.

Flow conditions were varied by the nozzle cycle (section II. C) and the wind tunnel Mach number of $0.1,0.2$, and 0.28. Since the wind tunnel is open to the atmosphere, the ambient temperature and pressure fluctuate with 
prevailing conditions. However, the ambient temperature turned out to be remarkably stable during the course of the experiment and only varied by about \pm 10 degrees typically from day to day.

Detailed geometry modifications were also tested including a fillet on the pylon-core nozzle body junction and an extended pylon compared to the standard length pylon. Not all of the results of the modifications are reported here since the general conclusions are not altered.

\section{Nozzle Cycles}

The nozzle cycle for BPR five (see Table 2) was taken from the same AST study that produced the original hardware design for the baseline nozzles. This cycle has been used previously in a study of high bypass ratio jet noise during the AST program ${ }^{6}$. The BPR eight cycle (see Table 3) used in this study is an updated version of the cycle used in the AST program work in order to reflect a more relevant cycle. The same cycle was used whether the configuration had a pylon or not and therefore, the nozzle exit conditions were also the same. As described in the discussion of Table 1, this meant that for a given baseline to pylon configuration comparison the fan area was different and therefore the actual thrust of the pylon configuration was less. As will be discussed in the next section, the acoustic data were scaled differently in order to allow an acoustic comparison on an equal thrust basis.

\section{Acoustic Data Processing}

Acoustic data were collected with a 28 microphone sideline array located 11.54 feet from the centerline axis of the model. Microphones were $1 / 4$ inches in diameter, operated with the grid caps removed, and calibrated with a piston phone and electrostatic calibrator before and after the test. Acoustic data was processed using both GE and NASA procedures and using different shear layer corrections. In general, while there are differences in the results from the different processing, the conclusions concerning changes between configurations are not altered. Therefore, data presented in this paper uses the GE process with the Amiet point source ${ }^{7}$ model for the shear layer correction. Acoustic data shown in subsequent sections are processed to $1 / 3$ octave bands and include corrections for the microphone calibration, wind tunnel background noise, a Doppler shift to the spectral data, and atmospheric absorption to acoustic standard day conditions using the Shields and Bass ${ }^{8}$ methodology. The data were scaled to the full-scale engine size using the varying scale factors of Table 1, and extrapolated to a distance of $1782 \mathrm{ft}$, typical of certification. This corresponds to an altitude of $1000 \mathrm{ft}$ and a ground sideline distance of $1476 \mathrm{ft}$. After the model scale data were transformed to full-scale, the EPNL was calculated by simulating an aircraft flyover at Mach 0.28 and using the procedure described in reference 9.

The repeatability of the acoustic measurements is approximately $\pm 0.4 \mathrm{~dB}$. Most of the test points were repeated several times. For the PNL and EPNL plotted here as a function of cycle condition, a linear fit is made through all available data points so differences between configurations can be made with more confidence by considering the trends demonstrated by all points along the cycle line.

The model scale nozzles are of almost identical total area as seen in Table 1. This implies less thrust from the higher bypass ratio nozzle. To make comparisons meaningful, the acoustic results were scaled to achieve equivalent ideal thrust at the takeoff condition. This would, in theory, allow either of the two bypass ratio nozzles to power the same aircraft with other practical issues ignored. This also means that for an equivalent ideal thrust the mixed jet velocity of the two bypass ratio nozzles will not necessarily be the same. With a scale factor of nine fixed for the BPR five baseline nozzle, different scale factor were calculated for the BPR five nozzle with a pylon, the BPR eight baseline, and the BPR eight nozzle with a pylon. This allows for the acoustic data to be scaled to a representative full scale at equivalent ideal thrust.

\section{Acoustic Results}

Even for the limited number of variables included in this experiment there are many comparisons that can be made in an attempt to quantify separately the various effects. The following sections present only a sample of the results that support the general conclusions found from the entire database. In general, the EPNL results for a given comparison are presented first in order to give the reader a summary of the relative merits of the various configurations to an aircraft application. Then more detailed physical interpretations of significant results are provided using PNL directivities and SPL spectra.

\section{A. Effect of Bypass Ratio}

One comparison of the two bypass ratio nozzles as a function of ideal thrust is shown in Figure 4 for the free jet Mach number of 0.28 that corresponds to a takeoff Mach number for a typical subsonic aircraft. The comparison is 
for the baseline nozzles without pylons. The comparison shows that at the highest ideal thrust corresponding to the takeoff cycle point, the EPNL is reduced by almost exactly $5 \mathrm{~dB}$ from the bypass ratio five to eight nozzle. This reduces to about $3 \mathrm{~dB}$ at the ideal thrust levels corresponding to the cutback cycle condition.

The directivity of the two baseline bypass ratio nozzles in terms of PNL is shown in Figure 5. Again, the differences between the two shows that the bypass ratio eight nozzle is approximately 3 to $8 \mathrm{~dB}$ lower than the bypass ratio five nozzle over the range of angles. Another key difference is how the angle of peak PNL is shifted slightly upstream by at least 10 degrees for the BPR eight nozzle compared to that for the BPR five nozzle. As will be seen shortly, the shift in directivity peak results from enhanced low frequency noise reduction by the BPR eight nozzle in the aft angles. The directivity of the BPR five nozzle also has a broader peak that ranges from a directivity angle of 110 to 130 degrees.

A final comparison of the two baseline bypass ratio nozzles is the spectra at a representative upstream angle $(\theta=$ $\left.60^{\circ}\right)$ and a downstream angle $\left(\theta=140^{\circ}\right)$, Figure 6 . The mixed velocity of the two nozzles at this takeoff cycle condition is approximately $1138 \mathrm{ft} / \mathrm{s}$ (BPR five) and $1031 \mathrm{ft} / \mathrm{s}$ (BPR eight). Differences in the two nozzle spectra are primarily in the lower frequency regime and can be attributed to the reduced the plume velocity of the BPR eight nozzle. In addition, the different size of the core nozzle (and resulting acoustic source volume from the core jet) between the two nozzles likely contributes to low frequency differences. The SPL differences diminish as frequency increases probably due to the fact that much of the high frequency noise is generated near the nozzle exit where the beneficial acoustic effects of the higher BPR have not yet been realized.

Tam and Pastouchenko ${ }^{10}$ have also reported the development of their prediction method for dual stream jets and have shown good agreement between these experimental results for the baseline nozzles of both bypass ratios and the predictions of spectra for downstream angles up to 110 degrees.

\section{B. Effect of Pylon}

The effect of the pylon was a central parameter in this experiment. The effect of the pylon was measured for baseline nozzles, core chevron nozzles, and fan and core chevron nozzle combinations. In this section the basic impact of the pylon on the baseline nozzles (without chevrons) will be described. The effect of the pylon on chevron nozzles will be covered in section III E.

For the BPR five nozzle, the effect of the pylon is shown in Figure 7. The pylon reduces the EPNL consistently by varying amounts over the cycle but generally about $1 \mathrm{EPNdB}$ relative to the baseline nozzle. The PNL directivity further characterizes the effect of the pylon for BPR five. Figure 8 shows the PNL directivity and, additionally, includes the case where an internal fillet was added to the junction between the pylon and core nozzle body. As the internal fillet wraps around the leading edge of the pylon inside the fan nozzle, the intent of the internal fillet is to reduce the strength of any horseshoe vortex that might form at that junction. Figure 8 shows that the pylon reduces the PNL by up to $3 \mathrm{~dB}$ in the downstream direction from an angle of 100 degrees and up. The impact of the pylon in the downstream angles supports the reasonable view that the pylon acts as a mixing enhancement device reducing the potential core length and plume velocities. This is supported by the computational results of Massey et. al. ${ }^{5}$ (for the same geometry and conditions) that showed the pylon reduced the potential core by a full core nozzle diameter relative to the baseline nozzle without pylon. The internal fillet has little effect on the directivity and little effect on the EPNL as well (not shown in Figure 7).

Figure 9 shows a sample spectra for the three cases of Figure 8 at downstream angle of 140 degrees where the PNL directivity showed significant differences in Figure 8. The pylon is again oriented at the 34 degree azimuthal angle. The spectra show that the pylon produces the noise reduction with reduced SPL over the frequency range up to $2000 \mathrm{~Hz}$. Again, the internal fillet produces little additional difference and will not be considered further.

The jet noise prediction method of Hunter ${ }^{11}$ has been used by Hunter and Thomas ${ }^{12}$ to predict the spectra and EPNL of the baseline bypass ratio five nozzle with and without the pylon. Spectral comparisons showed good agreement up to directivity angles of 120 degrees and together with the EPNL showed a matching drop in levels with the addition of the pylon.

The same sequence of three plots is now presented for the BPR eight nozzle. Figure 10 compares with and without pylon as a function of Vmix and shows a pylon effect where the pylon increases the noise slightly compared to the baseline nozzle. Recall from the BPR five results that the pylon actually decreased the noise. The increase for the BPR eight case is approximately $0.6 \mathrm{~dB}$, at the takeoff cycle condition. As Vmix is reduced the pylon effect is also reduced. This trend is generally true for other data not shown for BPR eight at other free jet Mach numbers and azimuthal angles. While not as strong, there is also evidence in the BPR five data that indicates the pylon acoustic effect is dependant on the cycle condition. A possible source of this cycle condition dependence of the pylon effect is the core and fan stream flow field changes around the pylon as the exhaust conditions change. Note from Tables 2 and 3 that the difference between the core and fan stream velocities is greater for the BPR five cycle 
points compared to the BPR eight cycle points. It is not possible to determine from these data, but interactions between the streams at the different velocities may partly explain both the direction and magnitude of the pylon effect for the BPR five and eight cases.

The PNL directivity shown in Figure 11 further illustrates the pylon effect for BPR eight. The directivity with pylon shows a consistent increase compared to the baseline over all angles up to 140 degrees followed by a slight decrease in noise. The noise reduction at angles above 140 degrees may indicate the same type of increased mixing attributed to the pylon in the BPR five case, but to a lesser degree. It is not know why the noise increases at angles less than 140 degrees, but is likely related to the interaction of the fan and core streams around the pylon as previously described. The spectra in Figure 12 show that the increase in the PNL with the pylon at 110 degrees is a consistent result over the entire frequency range out to about $4000 \mathrm{~Hz}$.

\section{Effect of Azimuthal Angle}

The introduction of non-axisymmetric nozzle geometry created by the pylon raised the possibility of azimuthal variation in the acoustic field. The computational results of Massey et. al. ${ }^{5}$ (for the same geometry and conditions) clearly showed the non-axisymmetry in the resulting downstream flow field further reinforcing the notion of azimuthal variation in the acoustic field. In this experiment this was investigated by measuring at three azimuthal angles of the pylon relative to the microphone shown in Figure 3. Figure 13 shows the EPNL as a function of Vmix for the three azimuthal angles for the BPR 5 nozzle with pylon. Immediately obvious is the lack of azimuthal variation at either of the two cycle conditions. Most of the configurations in this study were measured at various azimuthal angles and the results consistently showed an azimuthal variation not significantly above the experimental repeatability. Since other researchers ${ }^{3,4}$ have shown azimuthal variation on the order of 1 to $3.5 \mathrm{EPNdB}$, it is unclear why the results of this study do not show variations greater than about $0.5 \mathrm{~dB}$. However, these differences demonstrate that installation effects can vary from configuration to configuration and the need for further investigation into propulsion airframe aeroacoustic effects.

\section{Effect of Mach Number}

Most configurations were measured at three free jet Mach numbers 0.1, 0.2, and 0.28. An example is given in Figure 14 of the BPR eight nozzles, with and without pylon, at the lower and the higher free jet Mach numbers. First, as expected, the overall effect of increasing free jet Mach number is to lower the jet noise. Of interest here is the impact of free jet Mach number on the pylon effect. For this BPR eight nozzle at $\mathrm{Mfj}=0.28$, as shown previously, the pylon effect is to increase EPNL at the takeoff cycle condition by about $0.6 \mathrm{~dB}$; an effect that diminishes as Vmix is reduced. However, for the free jet Mach number of 0.1 the pylon effect is slightly less at the takeoff condition, about $0.4 \mathrm{~dB}$. Therefore, there may be a slight dependence on the free jet Mach, for a similar reason to the Vmix dependence, probably because the mixing in the jet is affected by the flow over the pylon.

\section{E. Effects of Chevrons}

Chevrons on the core and on the fan nozzle were measured for both bypass ratios. The impact of the pylon on the chevron effectiveness and the chevron alignment was also measured. The results presented below of the effects of fan and core chevrons for a similar nozzle without pylon are generally consistent with those reported by Janardan et. al. ${ }^{13}$ Furthermore, for a different nozzle and pylon design, the results for the baseline and core chevron nozzles with pylon reported below are also generally consistent with those reported in Martens ${ }^{3}$ except for the azimuthal variation as noted in section III C above. The additional contribution of the results below is to show the effect of the pylon by making direct comparisons on the same nozzle system with and without the pylon.

Figure 15 shows the effect of core chevrons compared to the baseline, without pylon, BPR five nozzle. At the takeoff Vmix, the core chevrons produce about 1.8 EPNdB reduction and diminishes to about $0.8 \mathrm{~dB}$ as Vmix is reduced to the cutback cycle condition. The chevrons are more effective at higher velocities. Also, on Figure 15 the effect of adding the pylon is plotted for the two alignments of the core chevrons relative to the pylon. The two positions involving aligning a trough of a chevron on the centerline of the pylon or aligning a tip of a chevron with the pylon centerline. This alignment effect, for exactly the same geometry and conditions, was computationally investigated by Thomas, et. al. ${ }^{13}$ and found to change the development of the flow field around the pylon closeout and into the plume. The acoustic experimental result of Figure 15 confirms that there is a difference created by the alignment. Having the chevron tip aligned with the pylon actually reduces the effectiveness of the core chevrons by about $0.4 \mathrm{~dB}$ while aligning the trough with the pylon improves the chevron effectiveness by $0.4 \mathrm{~dB}$ relative to the no pylon case. This effect is consistent over the range of Vmix shown. It should be noted that, while generally present in most cases, the trends described here are not always observed at all azimuthal angles and free jet Mach numbers. 
Figure 16 shows EPNL as a function of Vmix for cases with both fan and core chevrons for the BPR five configuration. Compared to the results shown in Figure 15, the addition of fan chevrons reduces the effectiveness of the core chevrons alone at takeoff levels of Vmix and even produces an increase at cutback levels of Vmix. Alignment of the fan chevrons relative to the core chevrons in the trough-to-tip orientation is slightly quieter over the entire cycle line compared to the tip-to-tip orientation, but the 0.2 to $0.3 \mathrm{~dB}$ benefit is within experimental uncertainty of a single data point. Adding the pylon to the fan/core chevron trough aligned combination produces no significant change to the EPNL. However, it will soon be shown that the pylon actually does produce significant changes in the details of the spectral content by altering the performance of the fan chevrons.

PNL directivities are now shown to better characterize the effects described in Figures 15 and 16 for the BPR five nozzles. Figure 17 shows that core chevrons reduce the PNL downstream of about 100 degrees by as much as 3 $\mathrm{dB}$ while adding the fan chevrons actually further reduces the PNL above 120 degrees by as much as $7 \mathrm{~dB}$ compared to the baseline. However, the fan chevrons also increase the PNL by up to $2 \mathrm{~dB}$ upstream of 100 degrees and thereby produce a net reduction in effectiveness of the fan and core chevron combination compared to just core chevrons alone.

The favorable alignment of core chevron trough with the pylon is shown in Figure 18 to be the result of a consistent but small decrease in PNL downstream of 100 degrees. The increased noise created by the core chevron with tip aligned to the pylon is seen to be the result of an increase in the PNL in the angles upstream of 130 degrees. The core and fan chevron combination results in an even larger increase in the same upstream angles.

A closer look at the SPL spectra with and without the pylon provides additional insight into the effect of the pylon on chevron performance for the BPR five nozzles. First, a sideline directivity angle of $\theta=110^{\circ}$, close to the peak PNL angle, is shown (Figures 19 and 20) and then a further downstream angle $\left(\theta=150^{\circ}\right)$ closer to the peak OASPL location where the jet noise tends to peak (Figures 21 and 22) is shown. Figure 21 demonstrates the typical desired effect of core chevron design, a reduction at low frequency (1-2 $\mathrm{dB}$ in this case) without accompanying increase at high frequency. The installation of the fan chevrons shows an additional reduction in the low frequency of 3-4 dB below the core chevron levels, but a detrimental increase of about $5 \mathrm{~dB}$ at frequencies above $700 \mathrm{~Hz}$.

At the same directivity angle of 110 degrees as in Figure 19, the spectral impact of the pylon interaction with the chevrons is shown in Figure 20. The addition of the pylon increases the low frequency levels for the two core chevron alignments, but the tip alignment is increased the most. For the fan and core chevron nozzle, the pylon again increases the low frequencies and completely eliminates all of the additional low frequency reduction seen in Figure 19. In all cases of Figure 20, the pylon has no effect on high frequencies above the cross over point of about $700 \mathrm{~Hz}$.

Farther downstream at 150 degrees, Figure 21 shows that again the core chevrons reduce the SPL by up to $5 \mathrm{~dB}$ up to about $1000 \mathrm{~Hz}$ while the fan and core chevron combination produces an additional reduction for a total reduction of up to $10 \mathrm{~dB}$. Figure 22 clearly demonstrates the impact of the pylon by again almost eliminating the low frequency reductions of the fan chevrons while not altering significantly the high frequency performance.

These spectra clearly illustrate that the pylon can affect performance of both fan and core chevrons. For the core chevron only case, the orientation of the chevron tip relative to the pylon centerline is important. Aligning the chevron tip directly below the pylon produces higher noise levels than aligning the trough. When fan chevrons are added to core chevrons, the effect is to reduce the desired low frequency benefit of the chevrons (that is, increase noise at low frequencies), but not significantly alter high frequency noise components.

Finally, the EPNL for BPR eight nozzles with core chevrons installed are shown in Figure 23. The core chevrons have much less effectiveness at the higher BPR. At the high Vmix levels the core chevrons have a benefit of only less than $0.5 \mathrm{~dB}$. While there is a reduction over the entire range of Vmix, the effect of the core chevrons diminishes quickly to an insignificant level as Vmix is reduced. The alignment of the core chevrons relative to the pylon creates a less than $0.3 \mathrm{~dB}$ effect and also quickly diminishes. The effect of adding fan chevrons to the core chevrons on the BPR eight nozzle is shown in Figure 24. There is a clear detrimental effect with a noise increase of about $1.0 \mathrm{~dB}$ at high Vmix and actually increasing as Vmix is reduced. A further detrimental interaction occurs when the pylon is added resulting in another $0.8 \mathrm{~dB}$ increase.

\section{Conclusions}

The current study contributes to the aeroacoustic understanding of the basic component of conventional propulsion airframe integration that is jet-pylon interaction. Significant changes resulting from the pylon are observed to noise radiated from axisymmetric separate flow baseline nozzles and to the effectiveness of chevron noise reduction devices. However, some changes are not consistent between bypass ratios indicating the complex nature of interactions resulting from propulsion airframe aeroacoustic effects. 
For the BPR five nozzle configuration, addition of the pylon reduces noise by approximately 1 EPNdB compared to the baseline case and there is little variation in azimuthal directivity. The pylon appears to impact mixing of the jet plume as evidenced by a shift of the peak PNL directivity in the upstream direction. The core chevrons alone produce a 1.8 EPNdB reduction compared to the baseline nozzle. Alignment of the chevrons relative to the pylon shows the general effect that aligning the trough of chevron with the centerline of the pylon enhances the chevron effectiveness by about $0.4 \mathrm{~dB}$ while aligning the tip of the chevron with the centerline of the pylon reduces the chevron effectiveness by about $0.4 \mathrm{~dB}$.

The addition of fan chevrons to the BPR five core alone chevron configuration reduces the effectiveness of the core chevrons on an EPNL basis at high power conditions and actually increases the noise over the baseline case at lower power settings. While the fan chevrons produce significant additional noise reduction in the low frequency regime, the noise reduction is offset in the EPNL computation by augmented noise in the high frequency regime. The addition of the pylon eliminates the low frequency reduction of the fan chevron, but does not significantly change higher frequencies.

For BPR eight, the effect of adding a pylon to the baseline nozzle is to slightly increase noise at higher cycle points. This increase diminishes as mixed velocity is decreased indicating a general dependence of the pylon effect on the cycle condition and resulting flow around the pylon. The core chevrons on the BPR eight nozzle had only a 0.5 EPNdB benefit at the takeoff cycle condition. The addition of the pylon has very little effect on the performance of the core chevrons. Fan chevrons significantly increase the EPNL of the BPR eight nozzle and the pylon further increases the noise for fan/core chevron case. There is very little acoustic directivity variation with azimuthal angle for either the BPR five or eight nozzle configuration.

\section{Acknowledgments}

The authors wish to thank the Jet Noise Laboratory staff for their many contributions to the planning, operation, and data processing required for the experiment that produced the results written in this paper. Special thanks is extended to Dr. Steven Martens of General Electric Aircraft Engines for contributing to the analysis, processing, and plotting on an equivalent ideal thrust basis. In addition, Dr. Martens made valuable suggestions used throughout the experimental effort.

\section{References}

${ }^{1}$ Thomas, R.H., “Aeroacoustics of Propulsion Airframe Integration: Overview of NASA's Research,” Noise Con Paper 2003105, presented at the 2003 Noise Con Conference, Cleveland, OH, June 23-25, 2003.

${ }^{2}$ Saiyed, N., Mikkelsen, K., and Bridges, J., "Acoustics and Thrust of Separate-Flow Exhaust Nozzles with Mixing Devices for High Bypass Ratio Engines," AIAA Paper 2000-1961.

${ }^{3}$ Martens, S., "Jet Noise Reduction Technology Development at GE Aircraft Engines." ICAS Paper 842, presented at the International Council of the Aeronautical Sciences, Toronto, Canada, September, 2002.

${ }^{4}$ Bhat. T.R.S., "Experimental Study of Acoustic Characteristics of Jets from Dual Flow Nozzles." AIAA Paper 2001-2183.

${ }^{5}$ Massey, S., Thomas, R., Abdol-Hamid, K., Elmiligui, A.: "Computational and Experimental Flow Field Analyses of Separate Flow Chevron Nozzles and Pylon Interaction.” AIAA Paper No. 2003-3212.

${ }^{6}$ Posey, J. W., Norum, T. D., Brown, M. C., and Bhat, T.R.: Jet Noise from Ultra-High Bypass Turbofan Engines. Presented at the $145^{\text {th }}$ Meeting of the Acoustical Society of America, Pittsburgh, PA, April 28 - May 2, 2003.

${ }^{7}$ Amiet, R.K. Correction of Open Jet Wind Tunnel Measurements for Shear Layer Refraction. AIAA $2^{\text {nd }}$ Aeroacoustics Conference, March 24-26, 1975, Hampton, VA.

${ }^{8}$ Shields, F. D. and Bass, H. E., "A Study of Atmospheric Absorption of High Frequency Noise and Application to Fractional Octave Bands of Noise," NASA Contractor Report 2760, 1976

${ }^{9}$ Harris, C.M., editor, "Handbook of Acoustical Measurements and Noise Control," McGraw-Hill, Inc., New York, 1991

${ }^{10}$ Tam, C.K.W., and Pastouchenko, N.N., "Fine Scale Turbulence Noise from Dual Stream Jets." AIAA Paper No. 20042871.

${ }^{11}$ Hunter, C. "An Approximate Jet Noise Prediction Method Based on Reynolds-Averaged Navier-Stokes Computational Fluid Dynamics Simulation.” Ph.D. Dissertation, George Washington University, January, 2002.

${ }^{12}$ Hunter. C., and Thomas, R., "Development of a Jet Noise Prediction Method for Installed Jet Configurations." AIAA Paper No. 2003-3169.

${ }^{13}$ Thomas, R.H., Kinzie, K.W., and Pao, S.P., “Computational Analysis of a Pylon-Chevron Core Nozzle Interaction.” AIAA Paper No. 2001-2185.

${ }^{14}$ Janardan, B.A., Hoff, G.E., Barter, J.W., Martens, S., and Gliebe, P.R., "AST Critical Propulsion and Noise Reduction Technologies for Future Commercial Subsonic Engines, Separate-Flow Exhaust System Noise Reduction Concept Evaluation." NASA CR-2000-210039, December, 2000. 
Table 1 Model areas for both cold and hot conditions and scale factors used for acoustic data processing

\begin{tabular}{|l|l|l|l|l|l|l|l|l|}
\hline BPR & Pylon & $\begin{array}{l}\text { Test } \\
\text { Point }\end{array}$ & $\begin{array}{l}\text { Cold } \\
\text { Model } \\
\text { Fan } \\
\text { Area, in }\end{array}$ & $\begin{array}{l}\text { Cold } \\
\text { Model } \\
\text { Core } \\
\text { Area, in }\end{array}$ & $\begin{array}{l}\text { Total } \\
\text { Model } \\
\text { Cold } \\
\text { Nozzle } \\
\text { Area, in }\end{array}$ & $\begin{array}{l}\text { Est Total } \\
\text { Hot } \\
\text { Model } \\
\text { Area, in }\end{array}$ & $\begin{array}{l}\text { Scale } \\
\text { Factor }\end{array}$ & $\begin{array}{l}\text { Full Size } \\
\text { Total } \\
\text { Area, in }\end{array}$ \\
\hline 5 & Yes & 15 & 26.87 & 10.75 & 37.62 & 37.23 & 9.00 & 3015.63 \\
\hline 5 & No & 15 & 28.84 & 10.75 & 39.59 & 39.21 & 8.77 & 3015.75 \\
\hline 8 & Yes & 5 & 30.07 & 7.56 & 37.63 & 37.43 & 9.72 & 3536.33 \\
\hline 8 & No & 5 & 32.32 & 7.56 & 39.88 & 39.69 & 9.44 & 3536.33 \\
\hline
\end{tabular}

Table 2 Bypass ratio five nozzle cycle

\begin{tabular}{|l|l|l|l|l|l|l|l|l|l|l|l|}
\hline Condition & $\begin{array}{l}\text { Test } \\
\text { Point }\end{array}$ & $\begin{array}{l}\text { Fan } \\
\text { NPR }\end{array}$ & $\begin{array}{l}\text { Fan } \\
\text { TT } \\
\text { R }\end{array}$ & $\begin{array}{l}\text { Est Fan } \\
\text { Velocity } \\
(\mathrm{ft} / \mathrm{s})\end{array}$ & $\begin{array}{l}\text { Est Fan } \\
\text { Flow } \\
\text { Rate } \\
(\mathrm{lbs} / \mathrm{s})\end{array}$ & $\begin{array}{l}\text { Core } \\
\text { NPR }\end{array}$ & $\begin{array}{l}\text { Core } \\
\text { TT } \\
\mathrm{R}\end{array}$ & $\begin{array}{l}\text { Est } \\
\text { Core } \\
\text { Velocity } \\
(\mathrm{ft} / \mathrm{s})\end{array}$ & $\begin{array}{l}\text { Est } \\
\text { Core } \\
\text { Flow } \\
\text { Rate } \\
(\mathrm{lbs} / \mathrm{s})\end{array}$ & BPR & $\begin{array}{l}\text { Est } \\
\text { Mixed } \\
\text { Velocity } \\
(\mathrm{ft} / \mathrm{s})\end{array}$ \\
\hline Approach & 1 & 1.27 & 582 & 680 & 9.16 & 1.15 & 1190 & 749 & 1.51 & 6.07 & 690 \\
\hline & 2 & 1.39 & 596 & 802 & 10.84 & 1.24 & 1240 & 944 & 1.98 & 5.47 & 824 \\
\hline Cutback & 5 & 1.51 & 612 & 904 & 12.18 & 1.33 & 1300 & 1107 & 2.28 & 5.34 & 936 \\
\hline & 12 & 1.63 & 629 & 993 & 13.3 & 1.445 & 1390 & 1294 & 2.61 & 5.1 & 1042 \\
\hline Takeoff & 15 & 1.75 & 647 & 1072 & 14.25 & 1.56 & 1491 & 1466 & 2.87 & 4.97 & 1138 \\
\hline
\end{tabular}

Table 3 Bypass ratio eight nozzle cycle

\begin{tabular}{|l|l|l|l|l|l|l|l|l|l|l|l|}
\hline Condition & $\begin{array}{l}\text { Test } \\
\text { Point }\end{array}$ & $\begin{array}{l}\text { Fan } \\
\text { NPR }\end{array}$ & $\begin{array}{l}\text { Fan } \\
\text { TT } \\
\text { R }\end{array}$ & $\begin{array}{l}\text { Est Fan } \\
\text { Velocity } \\
(\mathrm{ft} / \mathrm{s})\end{array}$ & $\begin{array}{l}\text { Est Fan } \\
\text { Flow } \\
\text { Rate } \\
(\mathrm{lbs} / \mathrm{s})\end{array}$ & $\begin{array}{l}\text { Core } \\
\text { NPR }\end{array}$ & $\begin{array}{l}\text { Core } \\
\text { TT R }\end{array}$ & $\begin{array}{l}\text { Est } \\
\text { Core } \\
\text { Velocity } \\
(\mathrm{ft} / \mathrm{s})\end{array}$ & $\begin{array}{l}\text { Est } \\
\text { Core } \\
\text { Flow } \\
\text { Rate } \\
(\mathrm{lbs} / \mathrm{s})\end{array}$ & BPR & $\begin{array}{l}\text { Est } \\
\text { Mixed } \\
\text { Velocity } \\
(\mathrm{ft} / \mathrm{s})\end{array}$ \\
\hline Approach & 1 & 1.26 & 640 & 701 & 10.3 & 1.13 & 1241 & 716 & 1.3 & 7.92 & 703 \\
\hline & 2 & 1.38 & 640 & 822 & 12.4 & 1.21 & 1320 & 918 & 1.5 & 8.26 & 832 \\
\hline Cutback & 3 & 1.46 & 640 & 888 & 13.6 & 1.27 & 1376 & 1046 & 1.7 & 8.0 & 906 \\
\hline & 4 & 1.54 & 640 & 945 & 14.7 & 1.34 & 1437 & 1179 & 1.9 & 7.73 & 972 \\
\hline Takeoff & 5 & 1.62 & 640 & 995 & 15.8 & 1.42 & 1498 & 1312 & 2.0 & 7.9 & 1031 \\
\hline
\end{tabular}
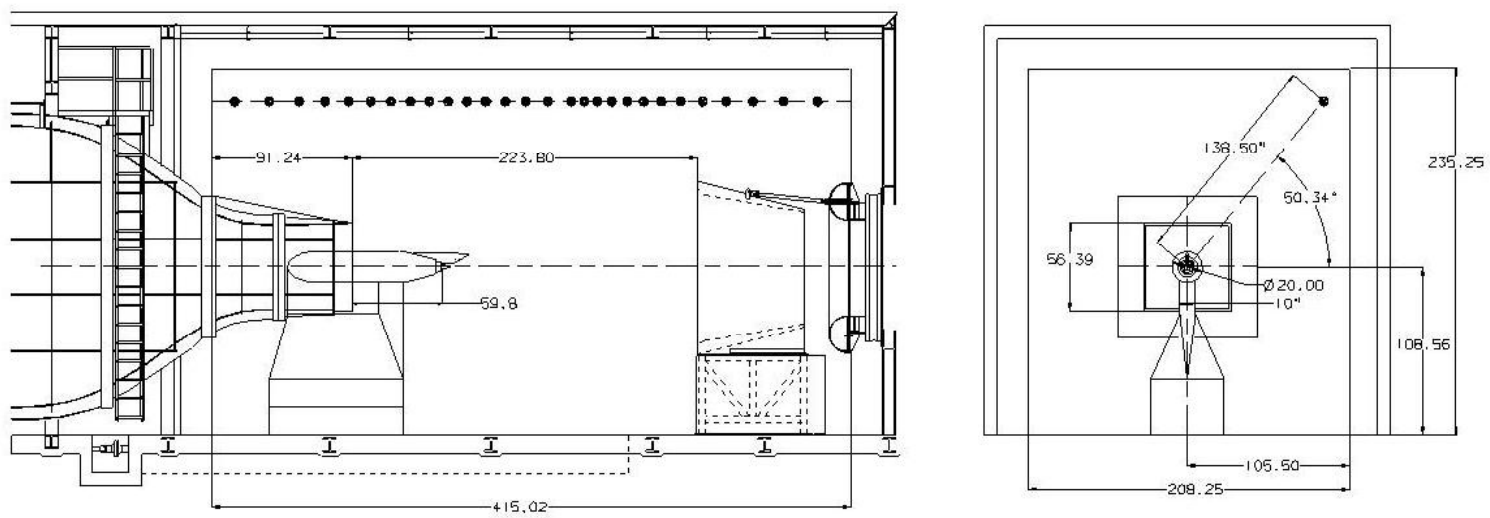

Figure 1 NASA Langley's Low Speed Aeroacoustic Wind Tunnel, side view of test section (left) with flow from left to right and end view looking upstream (right). Microphone array shown in upper right hand side of the end view. Dimensions in inches.

American Institute of Aeronautics and Astronautics 


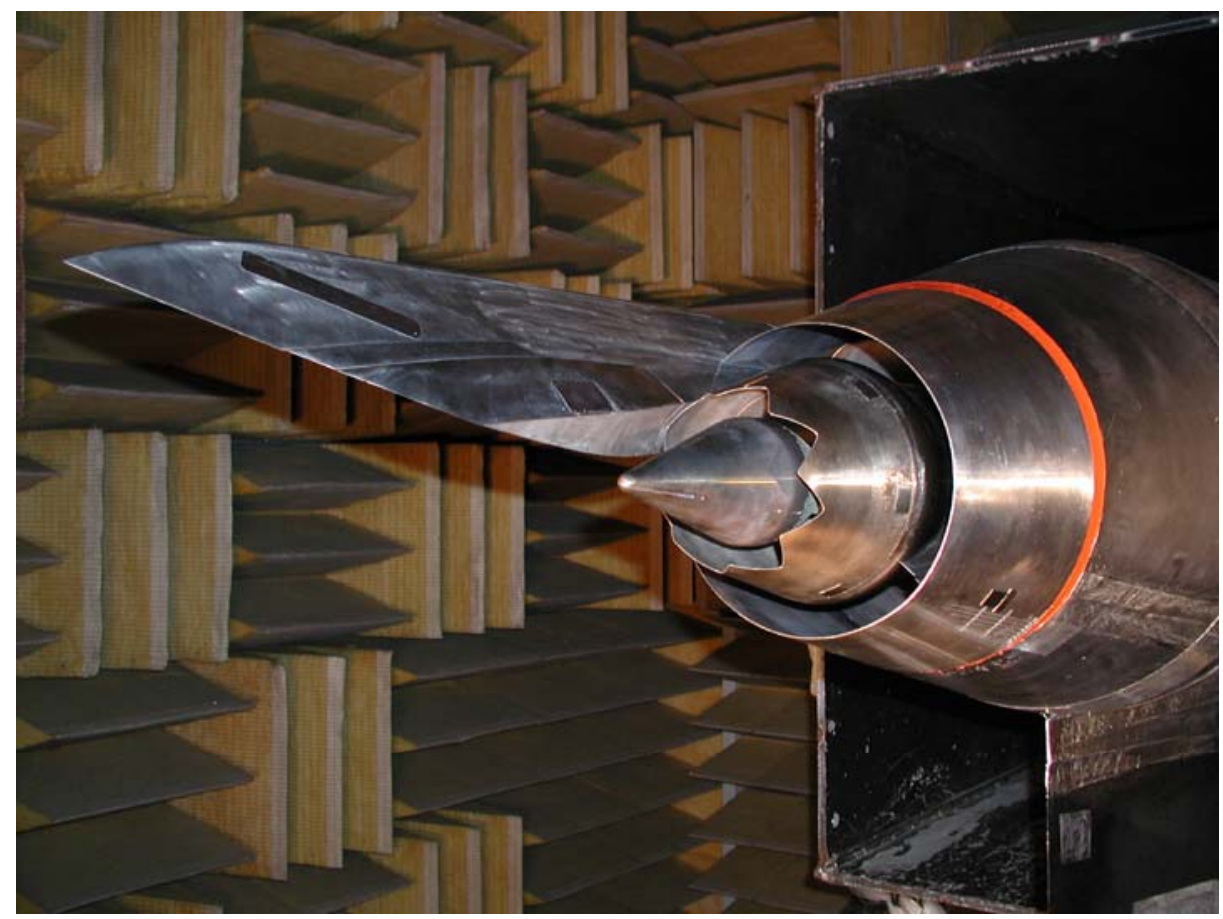

Figure 2 Bypass ratio five nozzle installed on the JES in the LSAWT. Eight core nozzle and baseline fan nozzle. Pylon is installed at the azimuthal angle of 34 degrees.

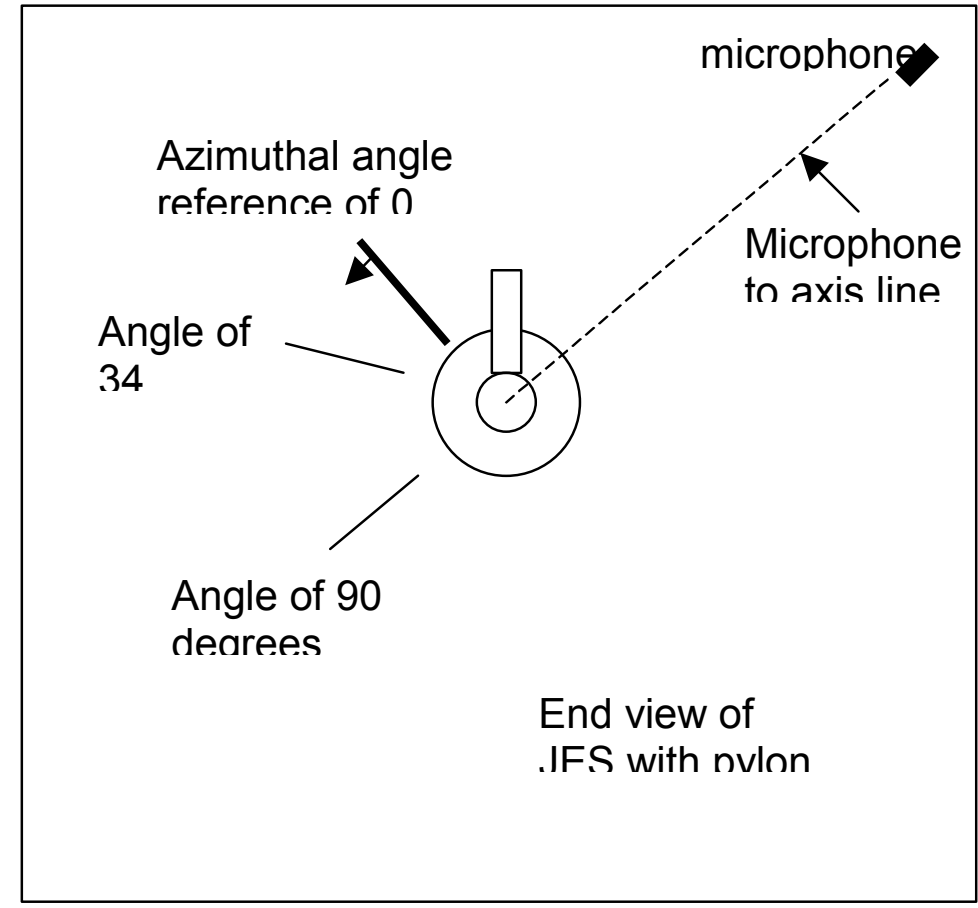

Figure 3 End view schematic of the test section looking upstream. The three azimuthal angles are identified with the microphones located in the top right hand corner. 


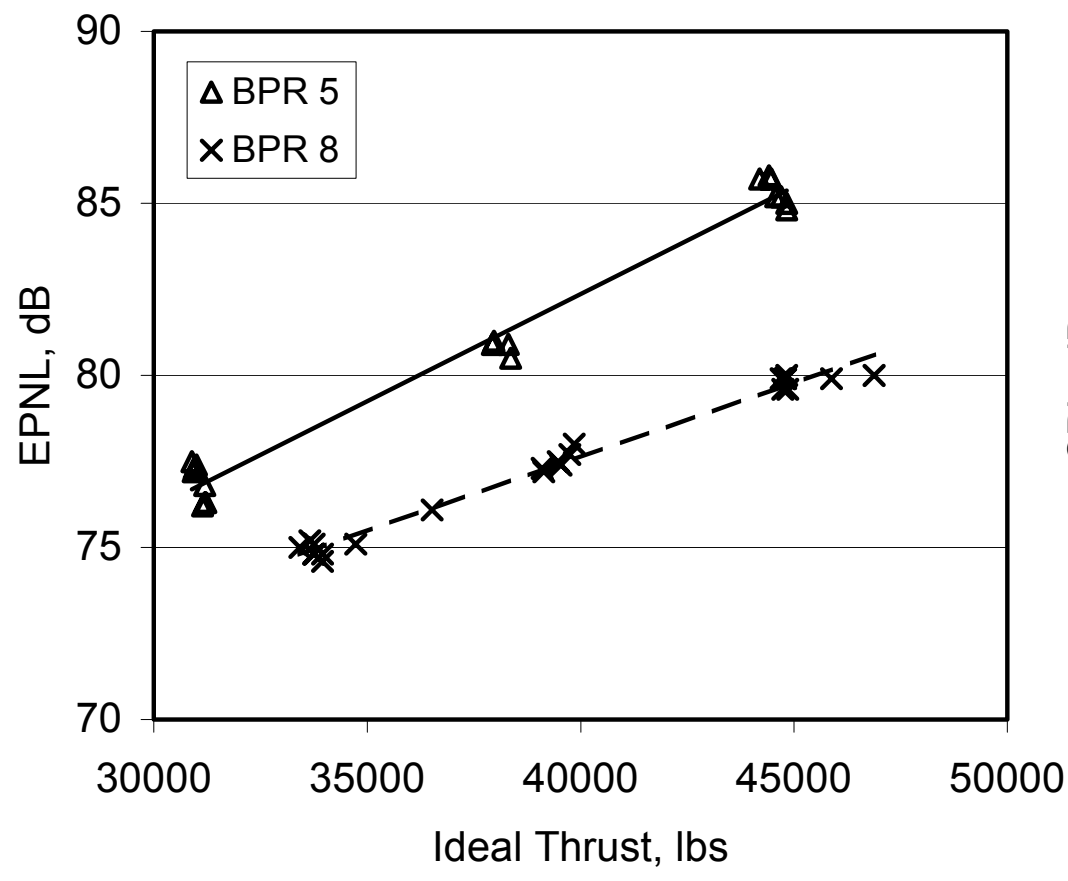

Figure 4 Effect of bypass ratio for baseline nozzles without pylon as a function of ideal thrust. Free jet Mach number of 0.28 .

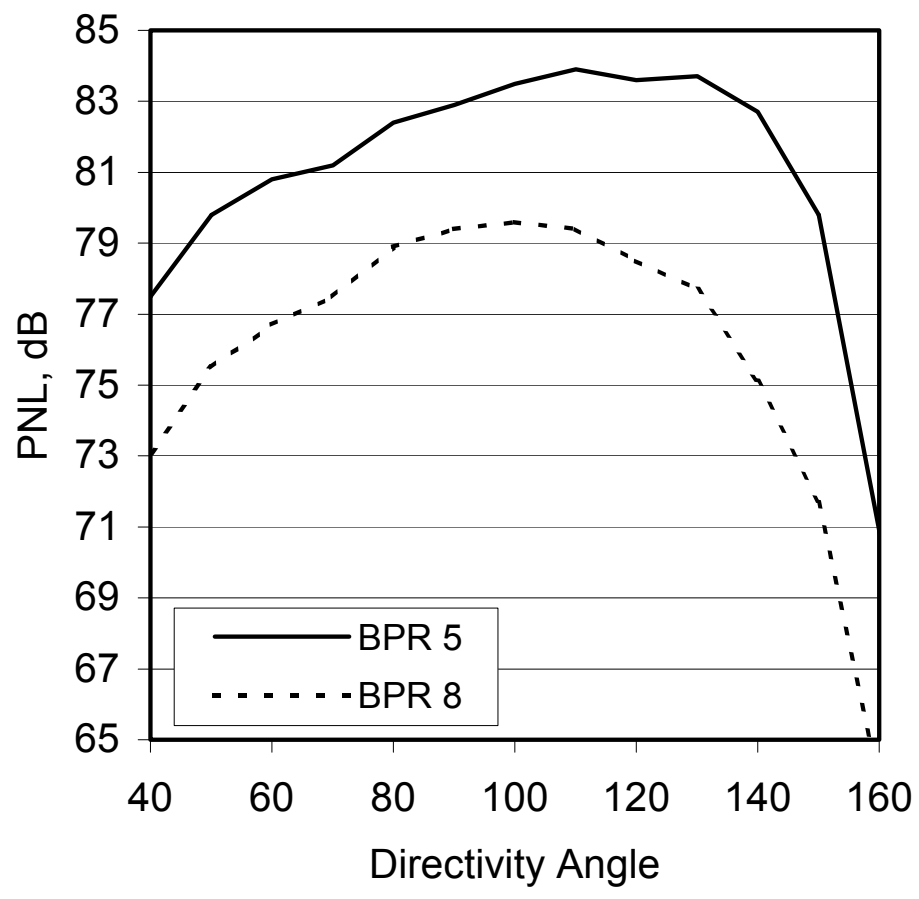

Figure 5 PNL directivity of the baseline, without pylon, nozzles for both bypass ratio five and eight. Free jet Mach number of 0.28. Takeoff cycle condition.

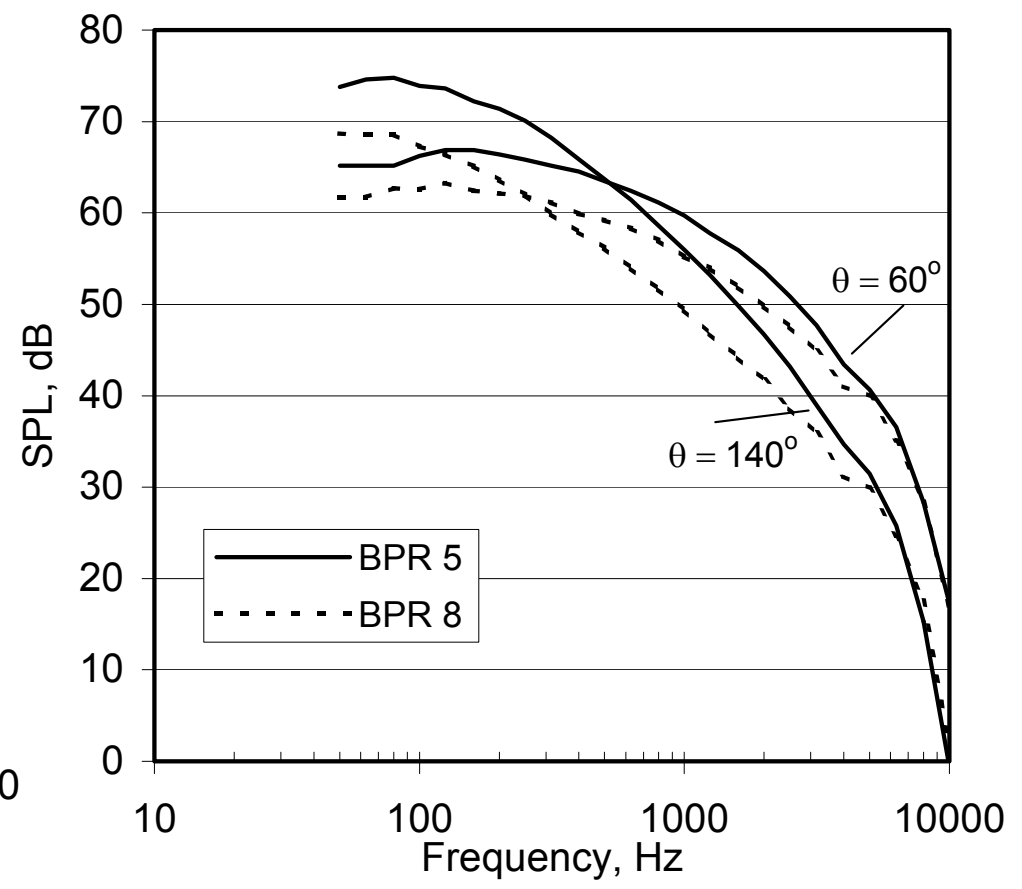

Figure 6 Full scale spectra at an upstream angle $(\theta=$ $\left.60^{\circ}\right)$ and at a downstream angle $\left(\theta=140^{\circ}\right)$ for both baseline (without pylon) bypass ratio five and eight nozzles. Free jet Mach number of 0.28 . Takeoff cycle condition.

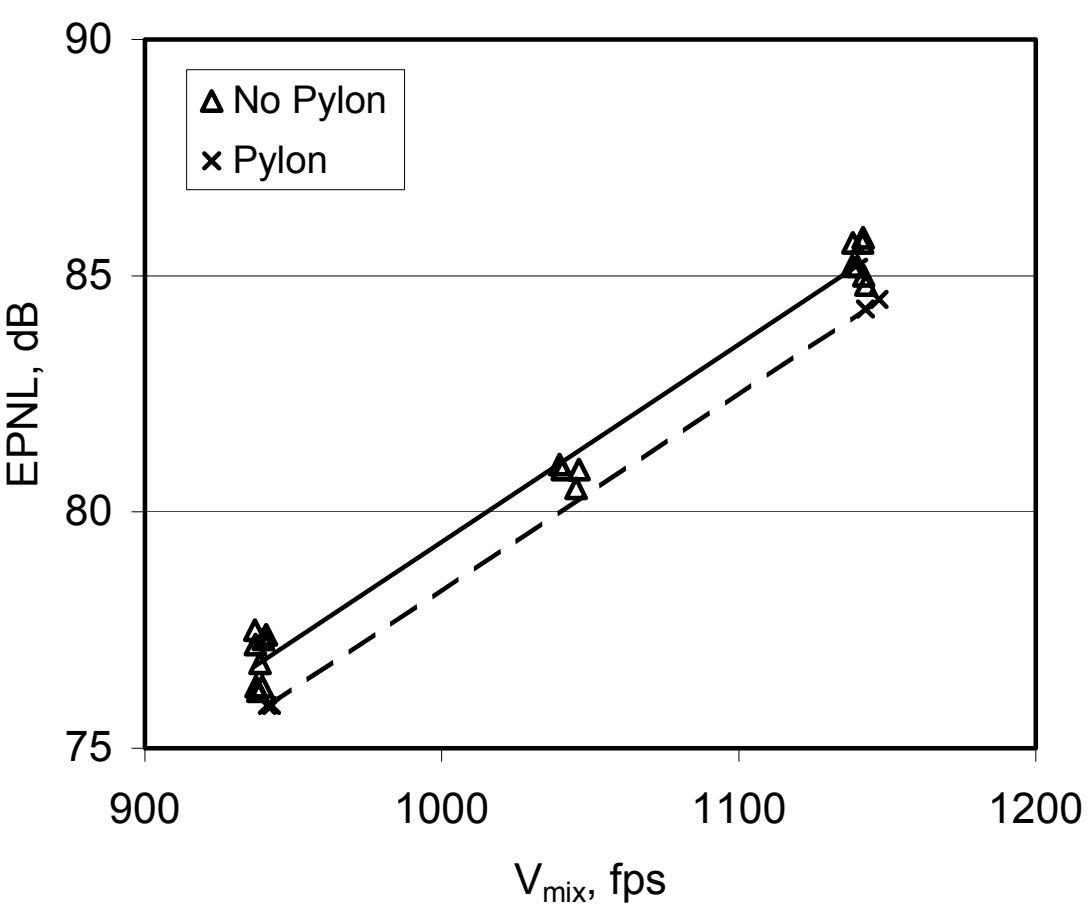

Figure 7 Effect of the pylon for the BPR five nozzle as a function of mixed velocity. Free jet Mach number of 0.28. Pylon at azimuthal angle of zero. 


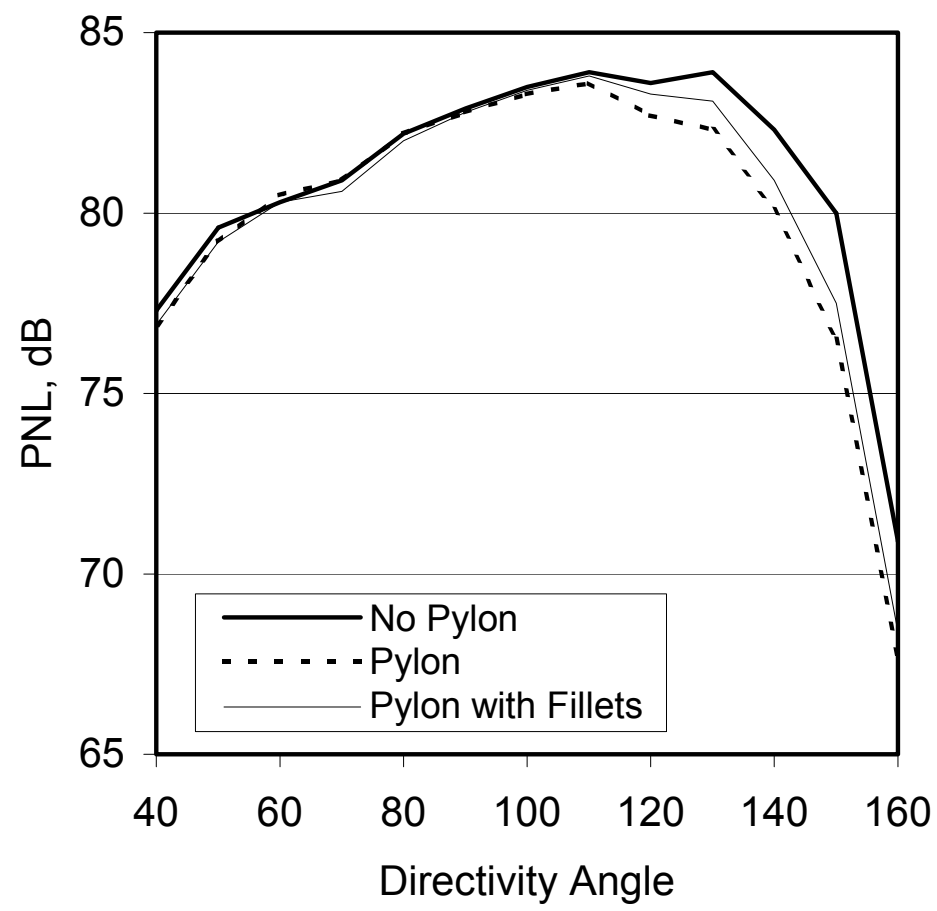

Figure 8 PNL as a function of directivity angle for BPR five nozzles: baseline with no pylon, with pylon, and with pylon and internal fillets. Takeoff cycle condition. Azimuthal angle of the pylon at 34 degrees. Free jet Mach number of 0.28 .

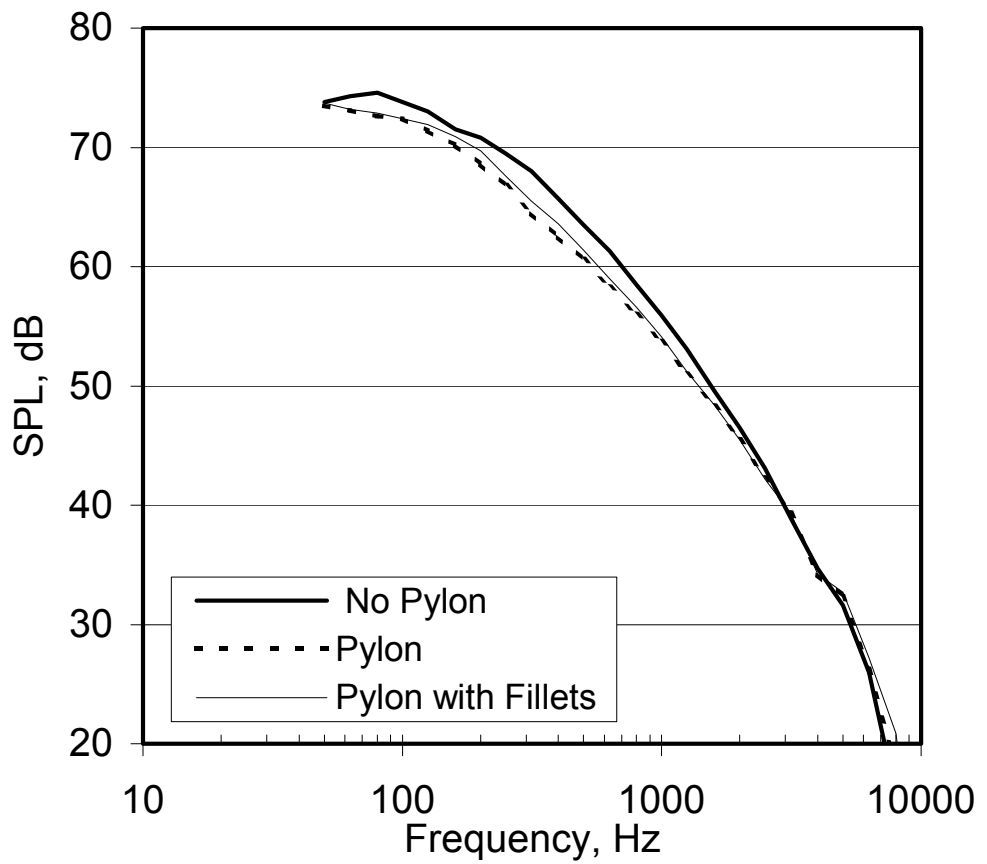

Figure 9 Spectra, full scale, for the BPR five nozzles: no pylon, with pylon, and pylon with internal fillets. Directivity angle of $\theta=140$ degrees. Takeoff cycle condition. Azimuthal angle of the pylon at 34 degrees. Free jet Mach number of 0.28 .

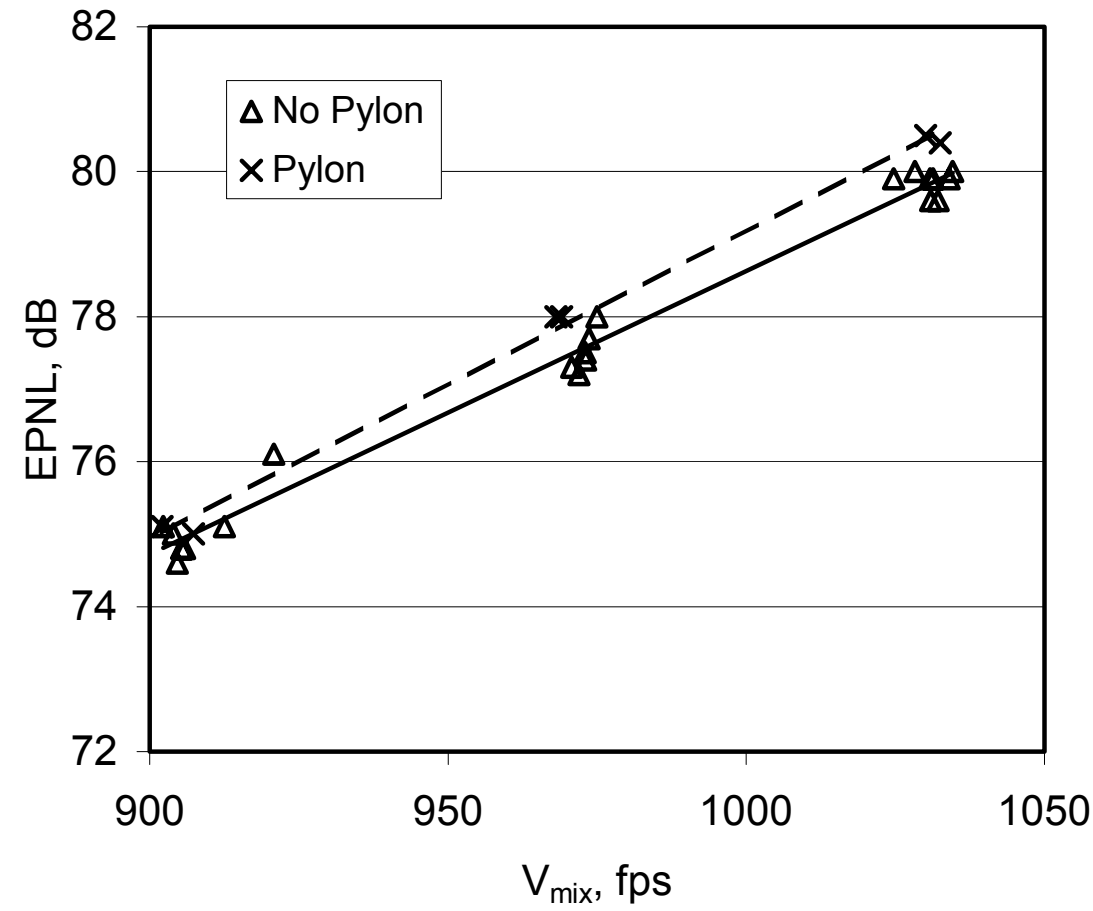

Figure 10 Effect of the pylon for the BPR eight nozzle as a function of mixed velocity. Free jet Mach number of 0.28. Pylon at azimuthal angle of zero.

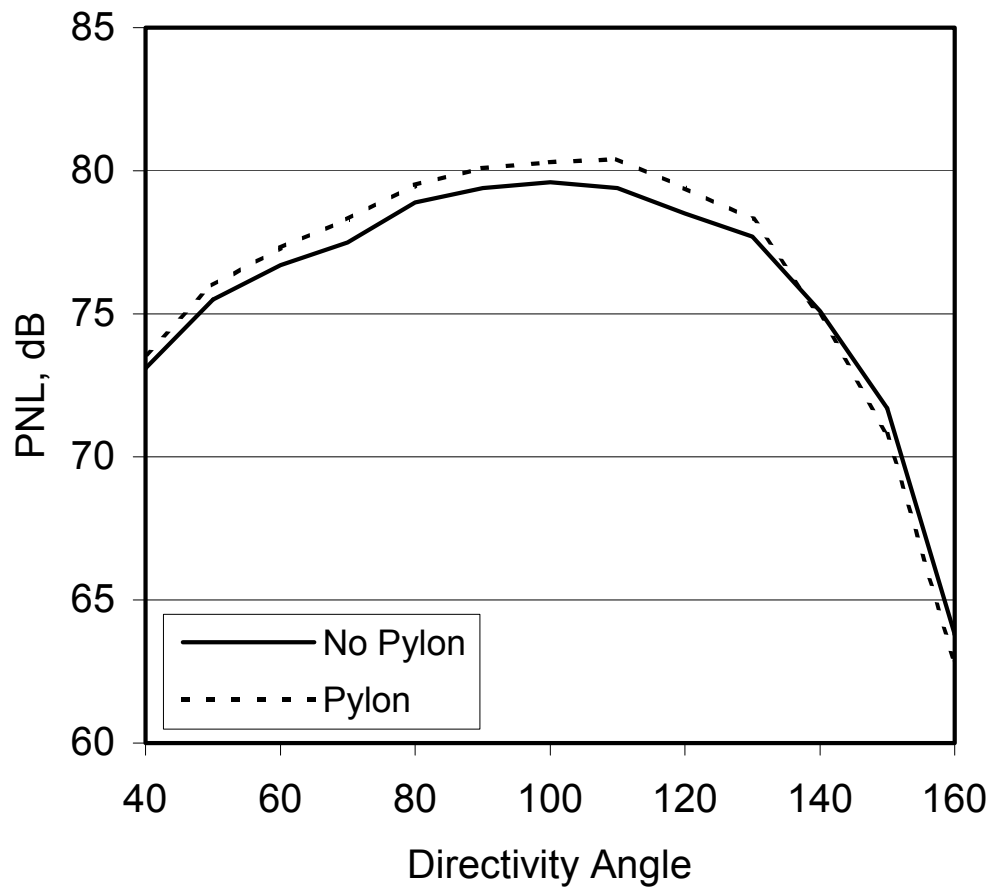

Figure 11 PNL as a function of directivity angle for BPR eight nozzles: baseline with no pylon, and with pylon. Takeoff cycle condition. Azimuthal angle of the pylon at 34 degrees. Free jet Mach number of 0.28 . 


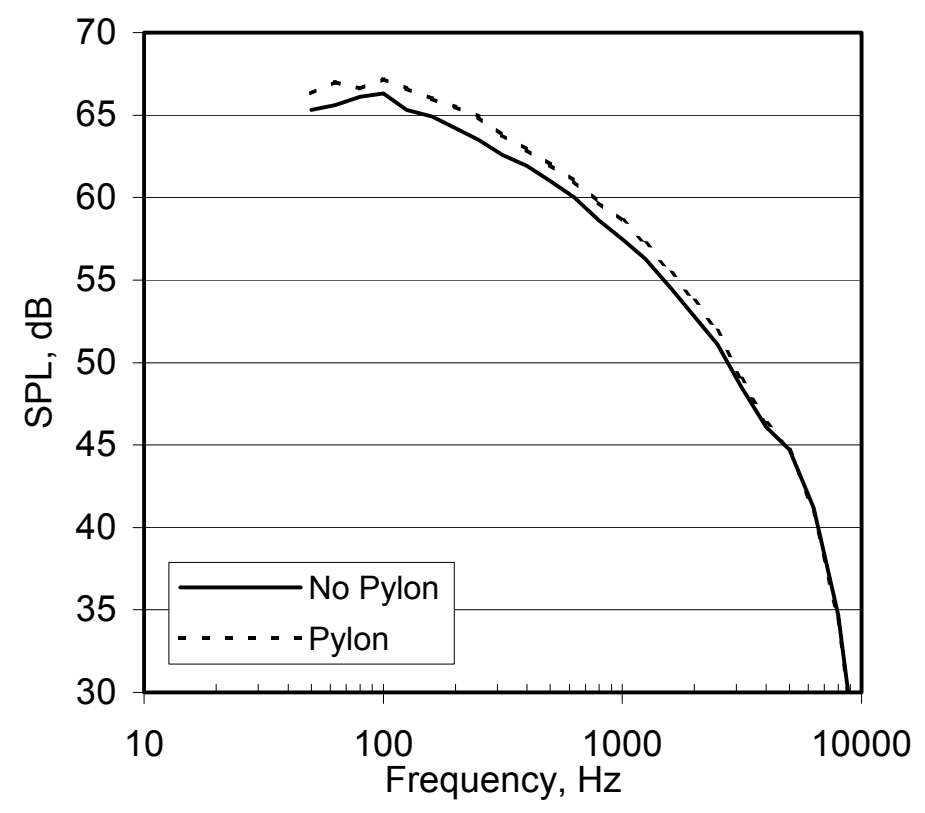

Figure 12 Spectra, full scale, for the BPR eight nozzles: no pylon, and with pylon. Directivity angle of $\theta=110$ degrees. Takeoff cycle condition. Azimuthal angle of the pylon at 34 degrees. Free jet Mach number of 0.28 .

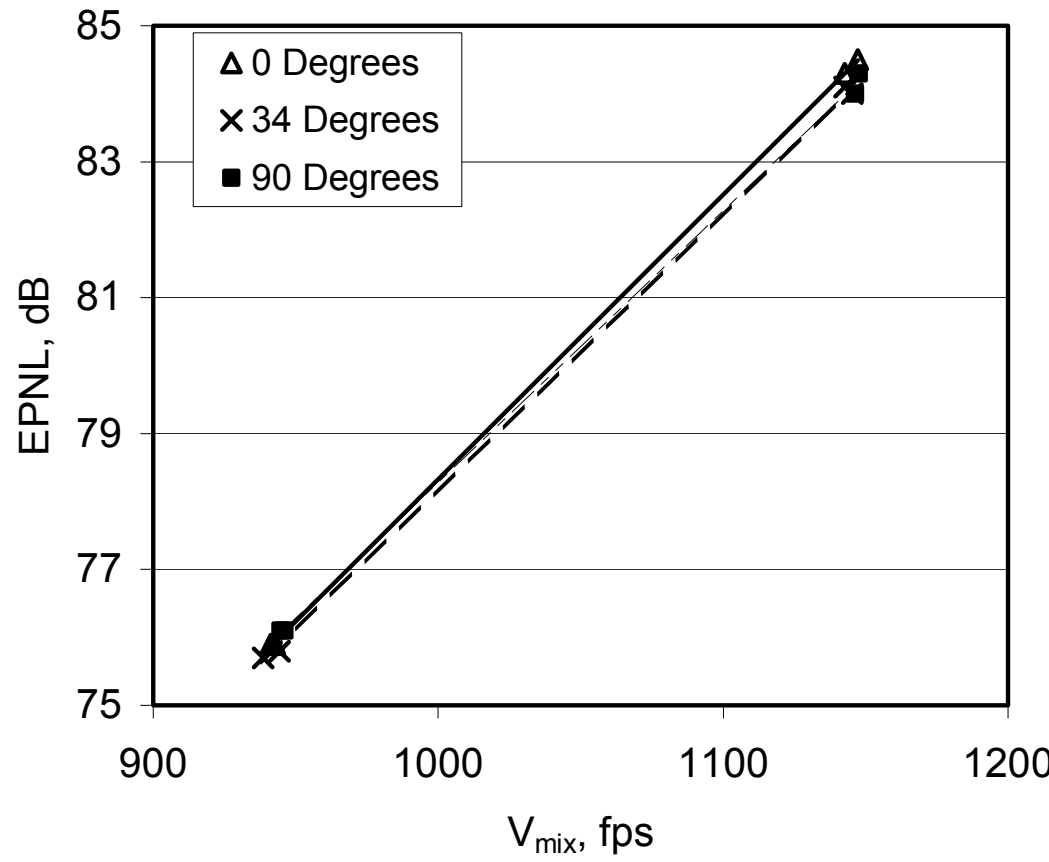

Figure 13 Azimuthal angle effect of the BPR 5 nozzle with pylon. EPNLdB as a function of $\mathrm{Vmix}$. Azimuthal angle of the pylon at 0,34 , and 90 degrees. Free jet Mach number of 0.28 .

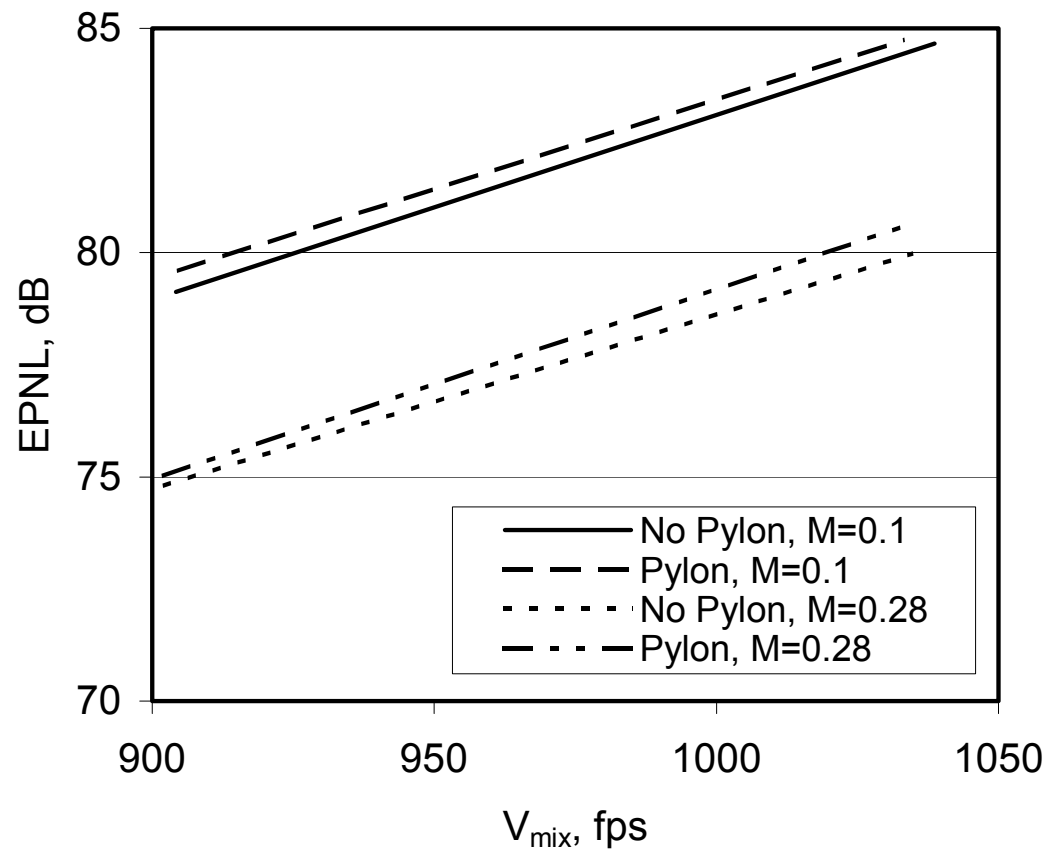

Figure 14 Free jet Mach number effect as a function of Vmix for BPR eight nozzle with and without pylon. Pylon at azimuthal angle of 0 degrees.

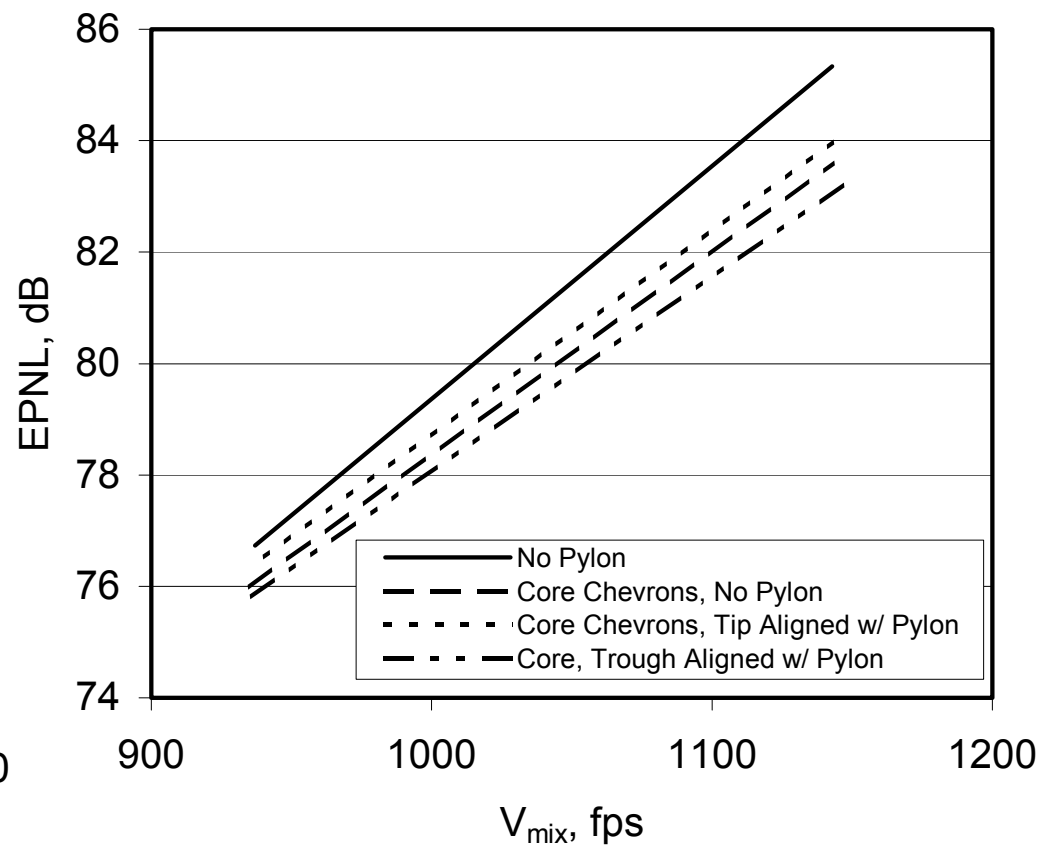

Figure 15 Effect of the pylon on core chevrons and the effect of alignment of core chevrons relative to the pylon. All BPR five nozzles, free jet Mach number of 0.28 , and an azimuthal angle of 0 for the pylon. 


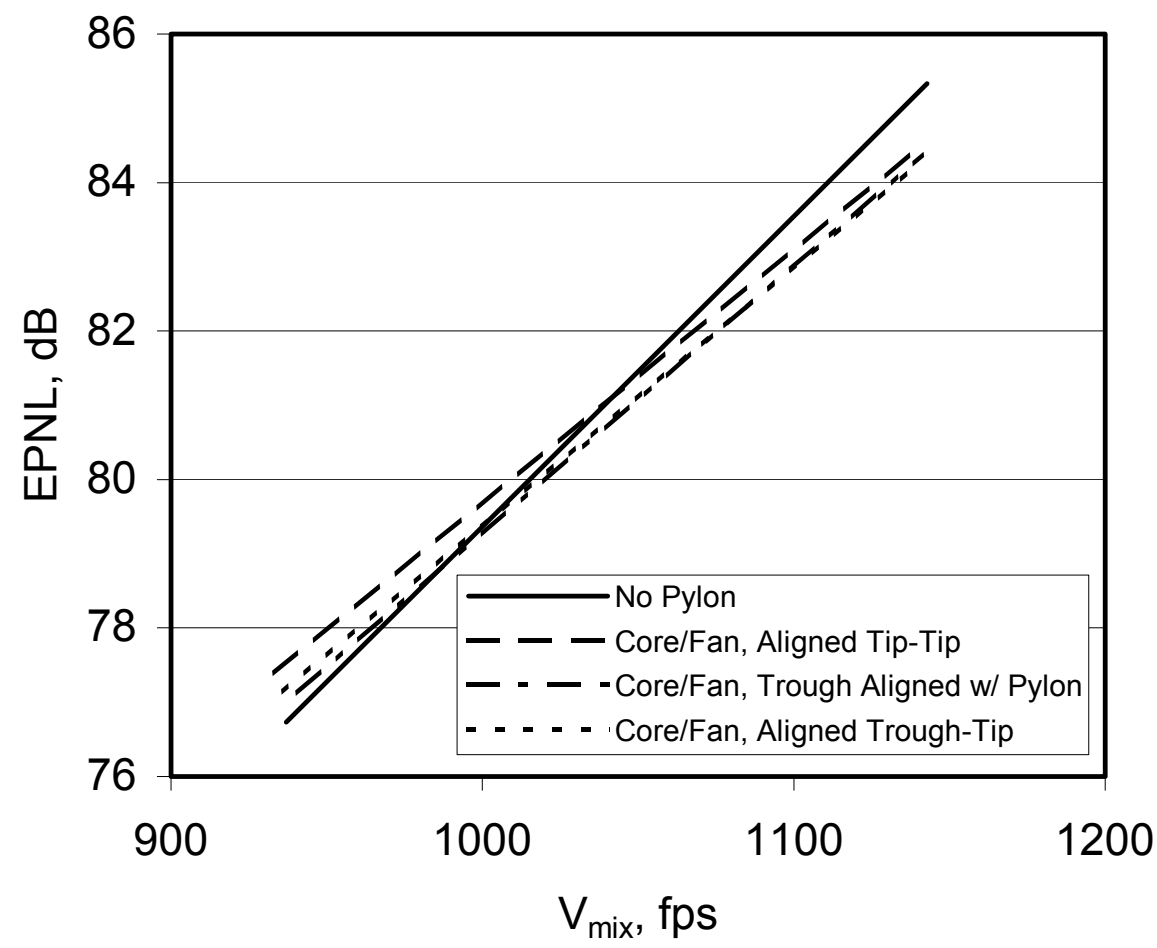

Figure 16 Effect of the pylon on the combination of core and fan chevrons and the effect of alignment of chevrons relative to each other and relative to the pylon. All BPR five nozzles, free jet Mach number of 0.28 , and an azimuthal angle of 0 degrees for the pylon.

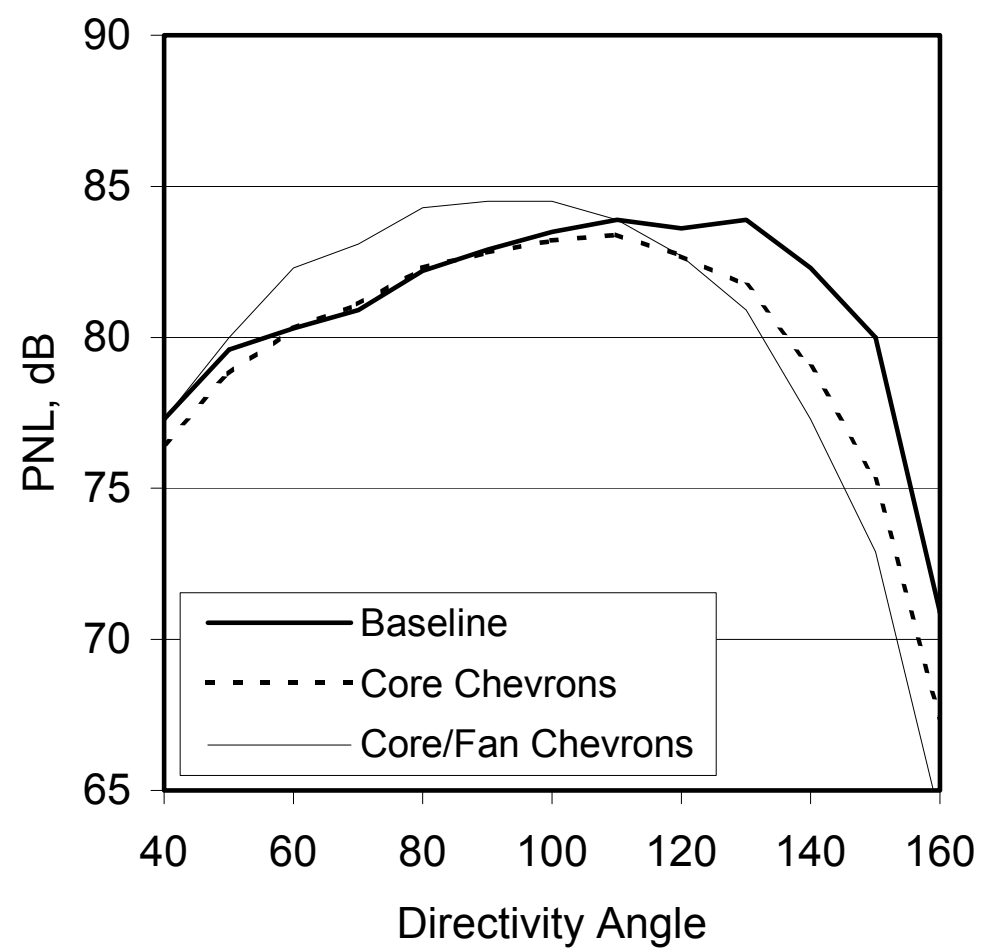

Figure 17 Effect on the PNL directivity of the core chevrons and the core and fan chevrons aligned trough to tip for the BPR five nozzle. Free jet Mach number of 0.28 , takeoff condition.

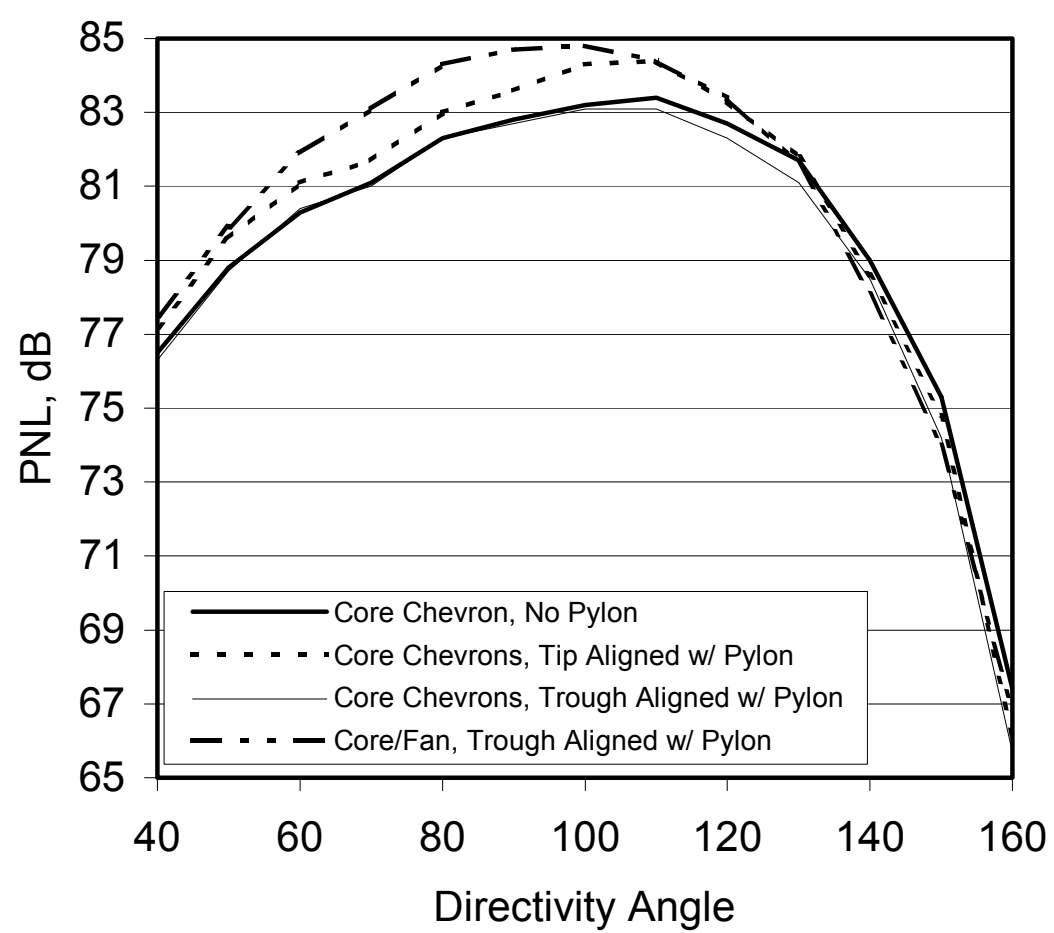

Figure 18 Effect on the PNL directivity of the pylon on core chevrons and the core and fan chevrons aligned trough to tip for the BPR five nozzle. Free jet Mach number of 0.28 , takeoff condition.

American Institute of Aeronautics and Astronautics 


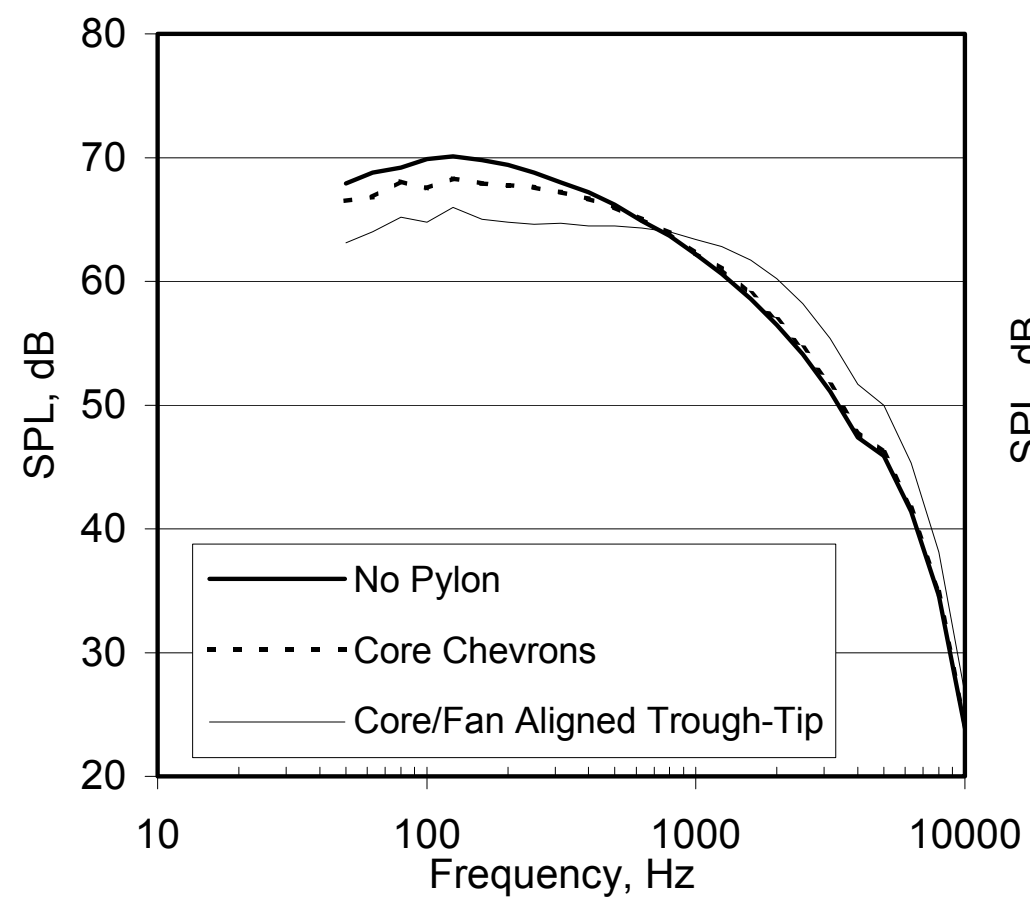

Figure 19 Spectra of the effect of core and core and fan chevrons at the downstream angle of $\theta=110$ degrees for the takeoff condition and free jet Mach number of 0.28. Bypass ratio five nozzles.

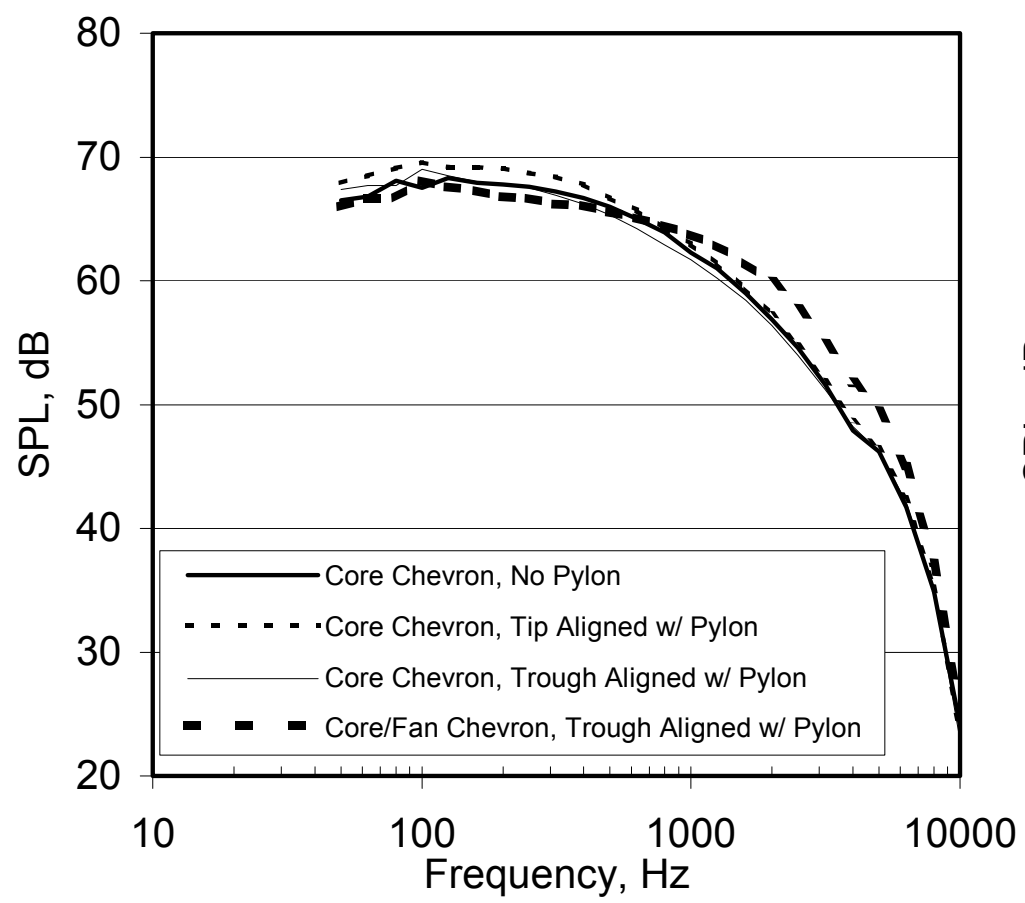

Figure 20 Spectral effects of the pylon on the core chevrons and alignment with the pylon and core and fan chevrons at the downstream angle of $\theta=110$ degrees for the takeoff condition and free jet Mach number of 0.28. Bvpass ratio five nozzles.

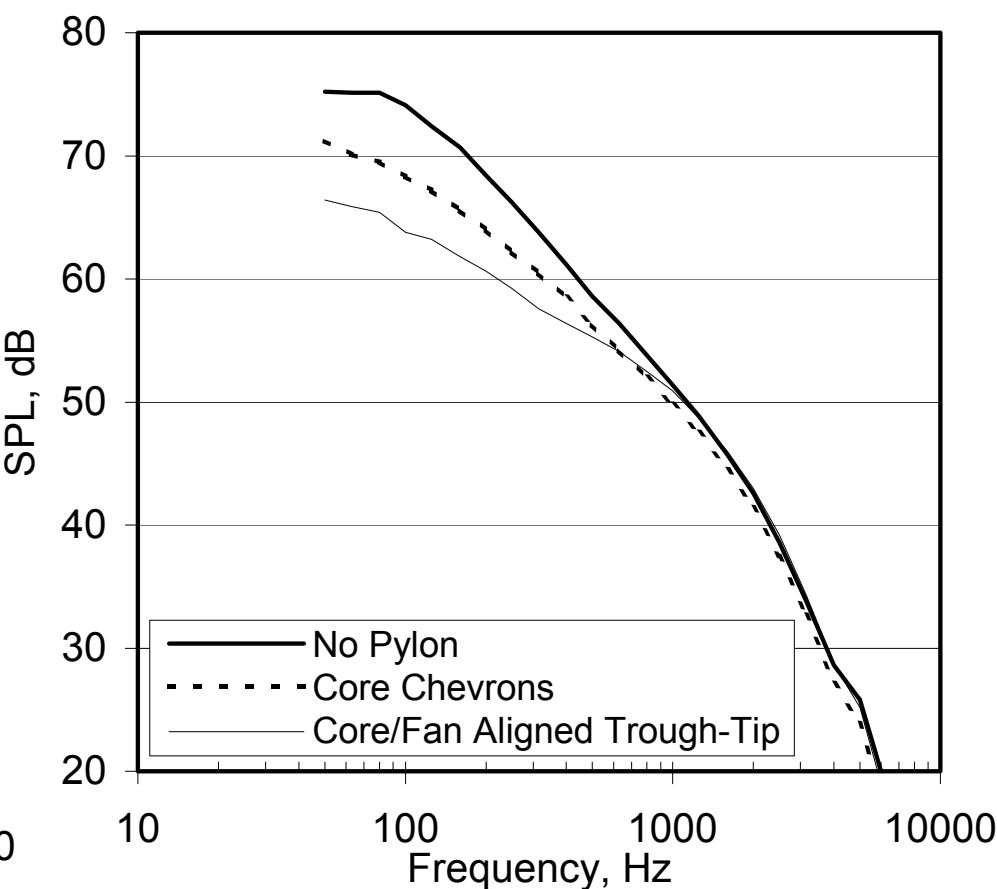

Figure 21 Spectra of the effect of core and core and fan chevrons at the downstream angle of $\theta=150$ degrees for the takeoff condition and free jet Mach number of 0.28 . Bypass ratio five nozzles.

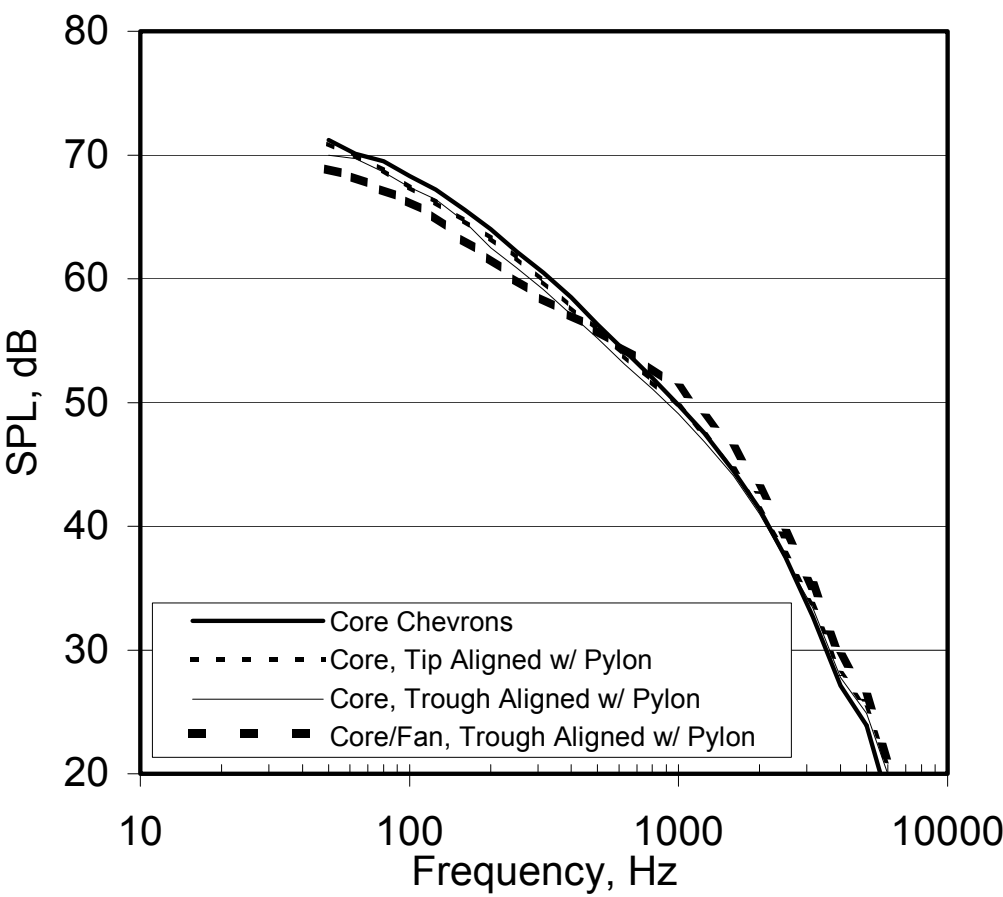

Figure 22 Spectral effects of the pylon on the core chevrons and alignment with the pylon and core and fan chevrons at the downstream angle of $\theta=150$ degrees for the takeoff condition and free jet Mach number of 0.28. Bypass ratio five nozzles. 


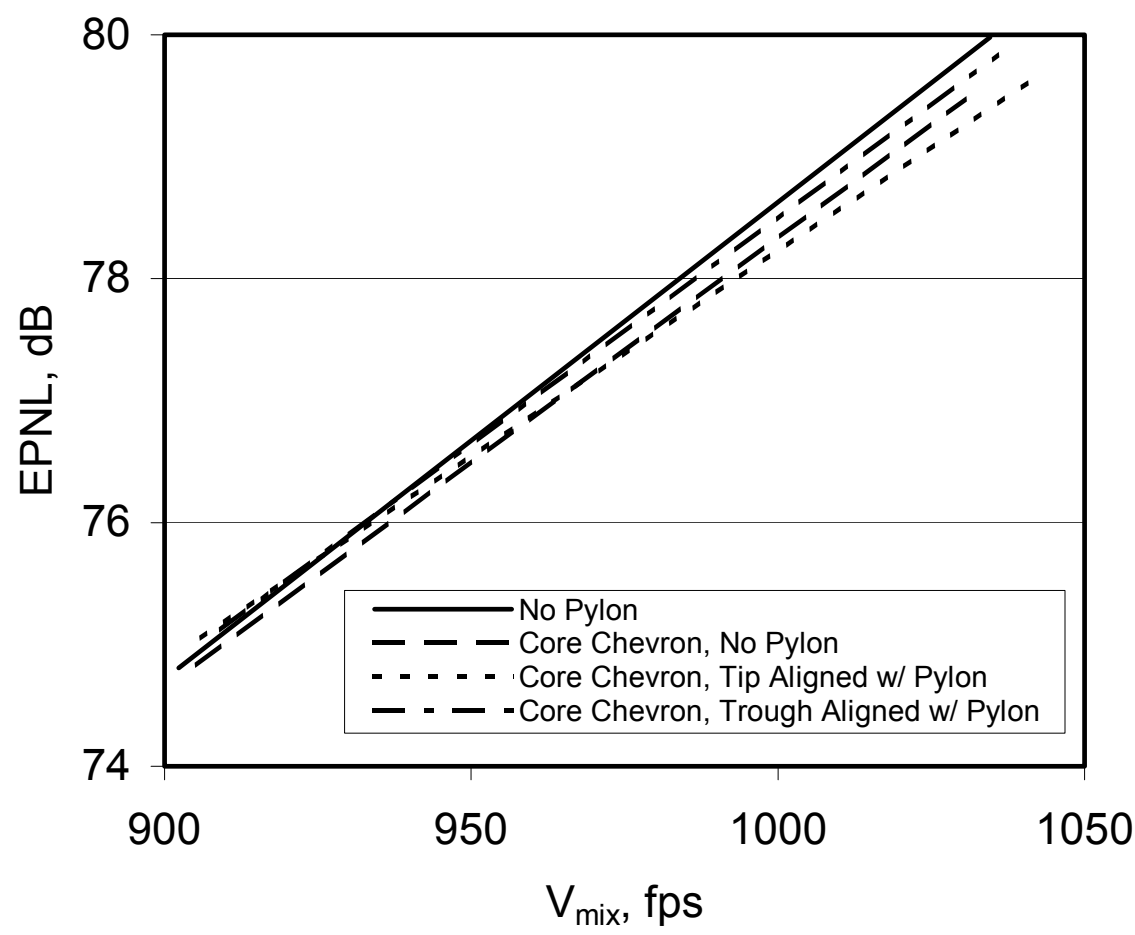

Figure 23 Effect of the pylon on core chevrons and the effect of alignment of core chevrons relative to the pylon. All BPR eight nozzles, free jet Mach number of 0.28 , and an azimuthal angle of 0 for the pylon.

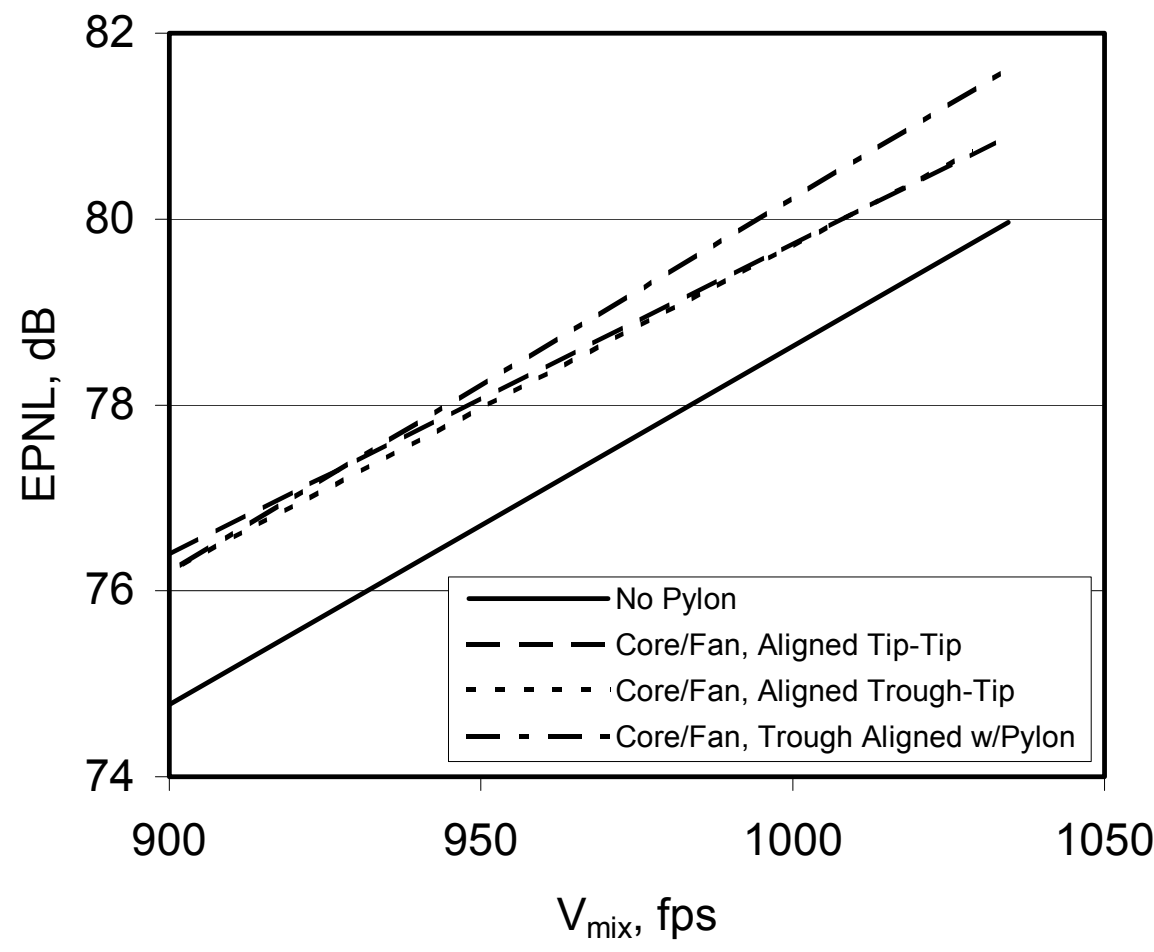

Figure 24 Effect of the pylon on the combination of core and fan chevrons and the effect of alignment of chevrons relative to each other and relative to the pylon. All BPR eight nozzles, free jet Mach number of 0.28 , and an azimuthal angle of 0 degrees for the pylon. 